\author{
Nicola Tondini, PhD \\ Assistant Professor \\ Department of Civil, Environmental and \\ Mechanical Engineering, \\ Via Mesiano 77- 38123 Trento, Italy. \\ Tel. $++39-0461-281976$ \\ Fax ++39-0461-282567 \\ e-mail: nicola.tondini@unitn.it
}

June 25, 2015

Dear Editor,

The research highlights of the paper 'Cross-sectional flexural capacity of cold-formed laterallyrestrained steel rectangular hollow flange beams' are listed below:

- Complete experimental analysis of the bending capacity of cold-formed steel profiles

- Tests on rectangular hollow flange I symmetric sections

- Favourable flexural performance/weight ratio for structural applications as secondary beams

- Good agreement between numerical and experimental results.

- EN1993 and Direct Strength Method predictions are on the safe side.

Thank you in advance for your co-operation in the matter.

Yours sincerely,

The authors 


\title{
Cross-sectional flexural capacity of cold-formed laterally-restrained steel rectangular hollow flange beams
}

\author{
Nicola Tondini ${ }^{\mathrm{a*}}$ and Andrea Morbioli ${ }^{\mathrm{a}}$ \\ ${ }^{a}$ Department of Civil, Environmental and Mechanical Engineering, University of Trento, Via \\ Mesiano 77, 38123, Italy
}

Corresponding author: *nicola.tondini@unitn.it; ph: +39 0461281976

\begin{abstract}
This paper presents the results of a comprehensive experimental-numerical study aimed at determining the flexural performance of cold-formed laterally-restrained steel rectangular hollow flange beams (RHFBs). Two RHFBs of different dimensions were considered as representative of typical secondary beams in small steel-framed houses. Results of the experimental study that consisted of i) material characterisation and ii) tests on full-scale specimens are thoroughly presented. Moreover, a numerical work was performed in order to develop a model able to reproduce the experimental outcomes and used to expand the available findings over a wider slenderness range through parametric studies.
\end{abstract}

Keywords: cold-formed steel profiles; rectangular hollow flange beams; flexural capacity; experimental tests; numerical modelling.

\section{INTRODUCTION}

The use of cold-formed steel sections in small houses is well established in North America and Australia but in Europe their exploitation is mainly limited to secondary elements of 
steel roof systems. Nowadays, even in Europe the use of such profiles is growing fast. Cold-formed steel sections are very sensitive to buckling phenomena - both local and global - because they are generally thin-walled profiles so that they can easily undergo cold working processing. Therefore, a lot of research has been addressed to understand their behaviour under compressive stresses owing to axial and/or flexural loads, see for instance review articles on numerical and experimental findings [1-4]. Nevertheless, their use as secondary beams often entails fully laterally-restrained conditions of the flange in compression owing to a steel sheeting that prevents lateral torsional buckling (LTB). Hence, the knowledge of the bending moment capacity of the section represents a key information [5]. In order to enhance bending moment performance, the use of hollow flange sections is tempting because most of the mass is located away from the strong section axis. Moreover, hollow flange sections also provide torsional stiffness. Thus, RHFBs can be a potential alternative to C- and Z-sections as well as to small hot-rolled sections thanks to: i) enhanced flexural behaviour associated with reduced weight; ii) ease of producing doubly symmetric geometry and iii) fast production times. Related research works were mainly devoted to the analysis of rectangular hollow flanges of channel sections [6-10] and to triangular hollow flanges of doubly symmetric I sections [11-13]. Numerical studies on symmetric rectangular hollow flange sections have been recently performed [14-18]. However, there is a lack of experimental testing on such profiles. On these premises, an experimental test programme on cold-formed steel RHFBs was planned in order to investigate their flexural performance by determining the section bending moment capacity. Furthermore, the experimental part is enriched by a numerical study with the following objectives: i) to calibrate a finite element model capable of reproducing the experimental evidences; ii) to perform a parametric analysis with the aim to broaden the results in terms of bending capacity to a wider range of slenderness ratios of the tube flanges; iii) to assess 
whether the prediction of the Eurocode EN1993 is adequate for such a cross section; iv) to evaluate how the Direct Strength Method (DSM) [2] estimates the flexural behaviour of RHFB cross sections.

The paper is articulated as follows: Section 2 describes in detail the experimental programme and the geometry of the specimens; Section 3 provides insight into the characterisation of the material properties; Section 4 presents and discusses the outcomes of the tests on the full-scale specimens; Section 5 introduces the numerical modelling and analyses the results of the model calibration; Section 6 describes the parametric studies, whereas Section 7 draws the conclusions and future perspectives.

\section{EXPERIMENTAL PROGRAMME}

The whole experimental programme was performed at the Laboratory of Structures and Materials Testing of the University of Trento. In detail, it was characterised by:

- 25 tensile tests on flat strips and on round corners of material coupons extracted from the specimens. The objective was to measure the actual tensile properties and to estimate the hardening induced by the cold working processing;

- 6 static monotonic tests on RHFBs.

\subsection{Specimen properties}

The section dimensions of the specimens were selected to be of common use in structural applications such as either purlins or secondary beams in small steel-framed houses. In detail, the section geometry is depicted in Figure 1. The nominal dimensions of the specimen sections are reported in Table 1. Both sections were overall classified as Class 4 according to EN1993-1-1 [19] considering an S235 steel grade: tube plates of Class 4 and web plate of Class 3 .

Gruppo Manni, an Italian steelwork company, was a stakeholder of this experimental study, that can be considered as a feasibility study, and provided the specimens. However, since 
the machine for fabricating the RHFBs from a unique coil was not available yet, the specimens were built by welding two structural tubes - produced by cold rolling - to a cut flat plate that constitutes the web. This fact prevented to introduce an intermediate stiffener on the outermost flat elements that are part of the tubes, as illustrated in Figure 1. This sort of detailing would be beneficial in order to reduce local buckling and crushing due to local effects of the flange in compression. Moreover, the way of producing the specimens was cause of higher imperfections relatively to those presumably expected if the appropriate cut machine had been used. In this respect, in agreement with the steelwork company, we convened to perform repeated tests - three for each section dimension - because some scatter in the results could appear. For instance, it was noticed increased imperfections owing to extensive welding between tubes and web plate and RHFB-240 profiles, endowed with smaller elements and thicknesses, were more prone to be affected by the production process. This aspect was observed in the tests and confirmed during the numerical calibration process presented later on in the paper.

Based on the previous considerations, a careful measurement of the actual geometric properties of thin-walled profiles is important because even small deviations from the nominal values could significantly affect their local and global behaviour. As a result, Table 2 collects the actual measurements of the section dimensions as well as the actual length of the specimen $L$. As expected, the actual values differ from the nominal ones and they are generally lower. Global imperfections were also measured even though they could not influence the behaviour of the beams during the tests because any possible global buckling mode was prevented. In any case, for sake of completeness, for all the specimens the global imperfections in the two principal axes were measured and they were less than L/2500. Only for the T01 RHFB-240 specimen a global imperfection about the weak axis of approximately L/1600 was found. 
It was difficult to precisely quantify local initial imperfections and consequently, they were not measured. Nevertheless and as already observed, RHFB-240 profiles were overall more affected by imperfections.

Figure 1. Geometry of: a) tested section and b) optimised section.

Table 1. Nominal section dimensions of the specimens. Dimensions in $\mathrm{mm}$.

Table 2. Measured section dimensions of the specimens. Dimensions in $\mathrm{mm}$.

\section{MATERIAL CHARACTERISATION}

A total of 25 tensile tests were carried out on material coupons extracted from the specimens. The tests were performed in accordance with EN ISO 6892-1 [20]. Both flats and corners were tested in order to establish the increase in yield strength owing to hardening induced by cold working and to obtain the stress-strain material relationships to be used in the numerical modelling. Corners were machined and tested to minimise eccentricities when loaded in the traction machine; in particular, the end parts were flattened. The yield strength $f_{y}$ of steels used for structural applications classified according to EN10025-2 [21] is defined as the upper yield strength $R_{e H}$. Nevertheless, due to cold working, the corners undergo plastic deformation; thus, the yield point may not be well defined and the $0.2 \%$ proof stress $\left(R_{0.2 p}\right)$ is consequently provided. As highlighted in Table 3 , a discrepancy among values of average yield strength between web and flange flats was observed, leading to so-called hybrid beams. This is particular evident for the RHFB-300 where the tube flat was characterised by significantly higher yield strength than the web. 
The stress-strain relationships obtained from tensile tests included flexural residual stresses whose magnitude is significant in cold-formed sections [22]. In fact, when the material coupons were extracted from the specimens, bending caused by the release of flexural residual stresses was clearly observed, as shown in Figure 2a. Then, once they were put into the traction machine by gripping the edges, flexural residual stresses were reintroduced through application of small loads. Conversely, membrane residual stresses were not measured because small with respect to flexural residual stresses, apart from corner regions [22]. The initial elastic modulus was found to be 202 GPa for the small tube, i.e. RHFB-240, and 203 GPa for the large tube, i.e. RHFB-300. Table 3 also reports on the average percentage elongation at failure $\varepsilon_{f}$ based on an $80 \mathrm{~mm}$ gauge length. Typical stress-strain relationships of the web, tube flats and tube corners are shown in Figure $3 a$. The corner tests confirmed an increase in yield strength due to cold working. The stressstrain constitutive laws of the RHFB-240 tube flats did not exhibited a sharp transition between the elastic and the plastic range - see Figure $3 b-$. This behaviour was less evident for the tubes of RHFB-300. In Figure 3a it may be observed that elongation at failure does not attain values given in Table 3 because the extensometer had to be removed some instants before failure in order to avoid any damage, as it is possible observe in Figure 2b.

Table 3. Tensile properties of steel.

Figure 2. a) Curving of material coupon upon machining from the cross sections; b) testing machine.

Figure 3. RHFB-240. a) Typical strain-stress relationship from tensile coupon tests; b) elastic-plastic transition of the tube flat. 


\section{STATIC TESTS}

\subsection{Experimental setup}

The experimental setup for static tests - Figure $4 \mathrm{a}$ - was conceived in order to induce a failure mode caused by the attainment of the maximum bending moment capacity of the section. Thus, each specimen was loaded according to a four-point bending scheme and was fully laterally-restrained by two HE300B profiles that assured restraint against LTB, as illustrated in Figure 4b. Low-friction sheets were placed between the specimen and the HE300B and initially not in contact with the specimen. Had LTB occurred, they would have allowed the full cross-section bending tests to continue without affecting them thanks to the inherent small friction coefficient. However, LTB was not observed in any test. Moreover, transverse stiffeners were welded at supports and at load points in order to prevent either web buckling or web crushing or web crippling caused by concentrated transverse loads. The load was introduced by means of a hydraulic actuator that was displacement-controlled at a speed of $0.5 \mathrm{~mm} / \mathrm{min}$. The total length of the specimens and the distance between the two point loads were selected within the recommendation limits provided in Appendix A.3.4 of EN1993-1-3 [23]. In detail, the length of the specimen should be at least 15 times its greatest transversal dimension and point loads should be applied to the specimen to produce a length under uniform bending moment at midspan of at least $0.2 \times$ (span) but not more than $0.33 \times($ span). Thus, the specimen length was $4.5 \mathrm{~m}$, the span $4 \mathrm{~m}$ and the region of constant bending moment equal to $1 \mathrm{~m}$. The end supports consisted of a hinge and a roller, respectively. In order to minimise local effects, load was applied through the web stiffeners, as depicted in Figure 4c. In detail, the spreader rigid beam (see Figure 4a) distributes the load to two metallic cylinders placed on the horizontal plates that are rested on the vertical lateral bracing plates visible in Figure 4c. 
The instrumentation applied to each specimen is shown in Figure 5 and comprised: displacement transducers (A2-A8) installed along the specimen in order to measure the vertical deflection; a displacement transducer (A1) at the roller support in order to measure the horizontal movement and strain gauges (E1 and E2) glued on the top and on the bottom flange of the midspan section in order to record strains. The applied load was registered by the actuator load cell.

Figure 4. a) Front and side views of the experimental setup. Dimensions in mm; b) T03 RHFB-240 setup; c) load application system through the web stiffeners.

Figure 5. Instrumentation setup. Dimension in $\mathrm{mm}$.

\subsection{Test results and discussion}

For both sections, some similar features in terms of flexural behaviour were observed. In particular, during the tests the specimens experienced well distributed local buckling waves on the compression flange, see as an example Figure 7a. This was expected because of the absence of an intermediate stiffener capable of increasing the critical buckling stress of the compression flange. Minor plasticization of the compression flange occurred early in the tests of RHFB-240 because more affected by imperfections introduced by the production process and more sensitive to local effects owing to small thicknesses. This led to a loss of stiffness early in the tests. Moreover, some minor plasticization was also observed outside the zone between the point loads owing to local imperfections associated with still significant bending moment close to the constant bending moment region, as illustrated in Figure 6c-d and Figure 7b. Nonetheless for each specimen, the eventual failure was caused by a formation of a main spatial plastic mechanism inside the zone of constant 
bending moment, as depicted in Figure 6a-b and Figure 7c-d. Particularly for RHFB-300, web buckling was also observed, as noticeable in Figure 7d.

Results in terms of bending moment-vertical displacement curves are illustrated in Figure 8 for RHFB-240 specimens and Figure 9 for RHFB-300 specimens, respectively. The bending moment was computed by multiplying the half of the measured applied load by the distance between the bearing and the point load. As soon as the ultimate bending moment was reached, it suddenly decreased without exhibiting an appreciable plateau, which is typical of Class 4 sections as defined in EN1993-1-1 [19].

Figure 6. RHFB-240: a) T02 failure mode; b) T02 enlargement of the main plastic mechanism at failure; c) T03 minor plasticization outside the point loads (left), main plastic mechanism at failure (middle), minor plasticization between the point loads (right); d) enlargement of the plasticization outside the point loads.

Figure 7. RHFB-300: a) T06 local buckling; b) T04 main spatial plastic mechanism; c) T04 highlight of the main spatial plastic mechanism (right) and of a secondary plastic mechanism (left); d) T06 failure mode with web buckling.

Figure 8. RHFB-240: bending moment-displacement curves.

Figure 9 RHFB-300: bending moment-displacement curves.

Moreover, in both Figure 8 and Figure 9 the average elastic moment $M_{y}$ and the average plastic moment $M_{p}$ of the specimens are shown. Both $M_{y}$ and $M_{p}$ were computed based on the actual geometric and mechanical properties. In this respect, the mechanical properties of tube flat coupons were used and no increase in yield strength in the tube corners was 
considered because membrane compressive residual stresses were not accounted for. In fact, as stated before, in cold-formed steel sections, compressive membrane residual stresses are small except for the corner regions where, owing to cold working, there is an increase in yield strength. Since these two effects tend to counteract one another [22] and the compressive membrane residual stresses were not measured, the elastic and the plastic bending moment were computed by disregarding the cold working effect in the corners. This reasoning is consistent with the one employed in the numerical analyses presented in Section 5. $M_{y}$ and $M_{p}$ were calculated for each specimen and then averaged to obtain one single value for both section geometries, i.e. RHFB-240 and the RHFB-300, respectively. Such curves are useful for identifying which level of bending moment was achieved by the specimens. $M_{y}$ was determined as the bending moment at which one fibre of the section attains first the elastic limit $\left(M_{y, w}\right)$. Since the beams were of hybrid type because the tubes and the web were made of different steel grades with $f_{y . t u b e f l a t}>f_{y \text {.web, }}$, it occurred that the elastic limit was reached before in the web than in the outermost fibre of the tube plate, as schematized in Figure 10. For this reason, and particularly for RHFB-300, the resulting elastic bending moment $\left(M_{y, w}\right)$ does not exploit the flexural strength of the tube whose stress can be still well within the elastic range. Thus, in order to mobilise the full strength of the outermost fibre of the tube plate a partial plastic redistribution in the web has to be accepted, where its part in compression may be affected by local buckling phenomena. Thus, an additional estimate of the elastic bending moment $\left(M_{y . f}\right)$ computed by the stress distribution shown in Figure 10 was provided. It considers gross section stresses. All RHFB-240 collapsed before attaining the average elastic moment whichever the way to compute it; thus, confirming the typical flexural behaviour of a Class 4 section [19], as depicted in Figure 8. For RHFB-300, it is interesting to note in Figure 9 that if we consider the elastic bending moment by definition, i.e. $M_{y, w}$, the section flexural behaviour of the 
specimens may appear of Class 3. Nevertheless, at $M_{y \cdot w}$, the tubes are in their elastic range with a significant reserve in flexural capacity before yielding that is not mobilised yet because $f_{y . t u b e f l a t}>>f_{y . w e b}$. In fact, if we now consider $M_{y . f}$, it may be observed that none of the specimens attained this level of bending moment hinting that local buckling affected the tube plate before achieving $f_{y . t u b e f l a t}$ as well as the web after yielding. The latter comparison is more meaningful considering that in bending capacity tests the flanges are the main resisting elements, whereas the web mainly carries shear. In this specific case, about $90 \%$ of bending is carried by the tubes and about $10 \%$ by the web. Consequently, the section can be actually classified as Class 4 . Moreover, such a behaviour was confirmed in the tests where local buckling of tube plate and of the web were clearly observed.

Figure 10. Stress distribution assumed for computing the section elastic bending moment.

The results of the tests are summarised in Table 4 where the ultimate load $\left(P_{u}\right)$, the ultimate bending moment $\left(M_{u}\right)$, the vertical displacement at maximum load $\left(\delta_{u}\right)$ and the mass per unit length $(g)$ of the specimens based on measured geometries are provided. The outcomes show that use of such profiles can be appealing in terms of the ratio flexural performance/weight in lieu of small hot rolled steel sections. In this respect, an estimate of weight savings is provided by determining through calculation the section modulus of IPE sections that would guarantee the average ultimate moment reached in tests by RHFBs considering the actual tube flat yield strengths: an IPE160A with mass per unit length equal to $12.7 \mathrm{~kg} / \mathrm{m}$, i.e. about $+20 \%$ with respect to $g_{R H F B-240}$, would be equivalent to the tested RHFB-240 section; and an IPE220 with $g=26.2 \mathrm{~kg} / \mathrm{m}$, i.e. about $+25 \%$ with respect to

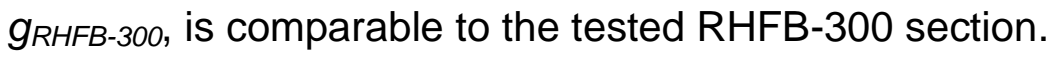


Table 4. Flexural performance of RHFBs.

Now, if we look at the strain gauge recordings as a function of the vertical displacement depicted in Figure 11, it is possible to note that for both beam types the strain order of magnitude is the same. Moreover, since the strain gauges were glued at the midspan of the two outermost tube flanges - see Figure 5 -, as soon as local elastic buckling initiated in the compression top flange the corresponding strain reading did not increase monotonically anymore and its evolution depends on how buckling developed locally. This phenomenon occurred at essentially the same compressive strain level for both sections because one of the key parameters that govern plate elastic buckling, i.e. the local slenderness ratio of the tube flange $-b / t \approx 50-$, is the same. Moreover, it is interesting to note that the theoretical elastic critical buckling strain $\varepsilon_{c r \text { thr }}$ of the tube outermost flange considering $k_{\sigma}=4$ is about equal to $1.45 \%$ o [24]. A lower experimental value of strain at which plate buckling occurred, $\mathcal{E}_{\text {cr.exp, }}$ is consistent considering the presence of imperfections and residual stresses.

Figure 11. a) T03 RHFB-240 strain-displacement curve; b) T04 RHFB-300 strain-displacement curve.

\section{NUMERICAL MODELLING}

The numerical model was developed to perform nonlinear analyses of the tests and was used to expand the available findings over a wider slenderness range through parametric studies. The multipurpose finite element software ANSYS [25] was employed. Model geometry, application of loads, boundary conditions and material properties were implemented to seek consistency with the real setup, actual dimensions of the specimens and mechanical properties of steel. All the assumptions and schematizations will be discussed in detail in Subsection 5.1-5.3. 


\subsection{Geometric model}

All beams tested in the experimental campaign - T01, T02, T03, T04, T05 \& T06 - were modelled through FE analysis. Shell elements were used in order to fully grasp all the main phenomena that govern the behaviour of the beam under bending, such as local buckling and plasticity diffusion [13]. The Shell 181 element of the ANSYS library [25] was used to model all the parts of the profile, i.e. the rectangular hollow flanges, the central web, the web stiffeners located at supports and at load points as well as the plates at supports, as shown in Figure 12. The Shell 181 element is a four-node element with six degrees of freedom at each node. It is well suited for moderately thick elements and for large rotation and/or large strain nonlinear applications. It is shear flexible and uses a uniform reduced integration method [25].

Figure 12. FE model of the RHFB-240.

A uniform mesh discretization was implemented for all the components of the model using roughly square shape elements (aspect ratio close to one), the side dimension of which is about $5 \mathrm{~mm}$ wide. Mesh refinement was locally applied to zones of high concentration stresses, i.e. zone of supports and point loads, as highlighted in Figure 13.

Figure 13. Mesh refinement and restraint conditions located at the base of the plate that redistributes reaction forces at supports. 
The geometry of each numerical model was developed consistently with the measured dimensions because small deviations from nominal values were detected, as described in Section 2.1. Local imperfections were not directly measured; nonetheless, they were introduced by means of an elastic buckling analysis. In particular, the lowest local buckling mode shape involving the compression flange was introduced into the model, as depicted in Figure 14

Figure 14. Lowest local buckling mode shape of the compression flange.

Moreover, an imperfection of the web was also implemented. The amplitude of the imperfections was selected by following the approach proposed by Schafer and Peköz [22]. In this respect, the maximum amplitude was assumed as a function of the element width according to the Eq (1) [22]:

$$
d=0.006 w
$$

where $w$ is the element width and $d$ represents the maximum imperfection amplitude. Analyses with different values of amplitude introduced in the web and in the top tube were performed and the ultimate load was compared with the experimental one. The amplitude values that better agreed with the experimental ultimate load corresponded to the maximum amplitude values as given in Eq (1) and they were then retained in all numerical simulations. For instance, the imperfection amplitude of the tube flange is about $d=0.6 \mathrm{~mm}$ for RHFB-240 and $d=0.9 \mathrm{~mm}$ for RHFB-300, respectively. In order to consider possible antisymmetric local buckling loads, the whole specimens were modelled. 


\subsection{Application of loads and restraints}

Restraints were applied to the plates that were used to distribute the reaction forces at supports. In detail, a roller and a hinge were modelled at the supports by assigning the relevant condition to all nodes along a line strip below the plate support located underneath the bottom tube flange, as illustrated in Figure 13. The plate and the bottom tube flange were connected together by means of rigid constraint equations - CERIG command [25] -. Finally, in order to prevent lateral torsional buckling and consistently with the experimental setup, restraints against horizontal displacement were punctually introduced along the top tube flange.

The load was applied by imposing increasing vertical displacement to the nodes of the web stiffeners located at half meter from the midspan. In this way, the evolution of the softening branch could be followed.

\subsection{Material properties}

The material mechanical properties implemented into the numerical model were derived directly from tensile tests on beam specimens drawn from the web and the tube flats. The cold working enhancement was not included in the corner zones because the membrane residual stresses were not modelled: in fact, they tend to counteract one another $[22,26]$ as described in Section 4. The material constitutive law included the flexural residual stresses, as described in Section 2. True stress - strain relationships were employed for material properties because more representative of the state of material in large strain analyses. They read [25]:

$$
\begin{gathered}
\sigma_{t}=\sigma_{e}\left(1+\varepsilon_{e}\right) \\
\varepsilon_{t}=\ln \left(1+\varepsilon_{e}\right)
\end{gathered}
$$


Where $\sigma_{t}$ is the true stress, $\sigma_{e}$ is the engineering stress, $\varepsilon_{t}$ is the true strain and $\varepsilon_{e}$ is the engineering strain.

The Poisson's ratio was taken equal to 0.30. The Multilinear Isotropic Hardening (MISO) material law was used for implementing the true stress - strain data. It allows including a user-defined stress-strain relationship by means of several linear segments. The MISO material is suitable for steel modelling because it relies on the Von Mises yield criterion. Moreover, an isotropic hardening rule was deemed adequate for the purpose because of the monotonic nature of the experimental tests.

\subsection{Analysis of the results}

In order to verify the accuracy of the numerical model, the ultimate moment capacity and the failure mode obtained from the numerical analyses were compared with the test outcomes. From Table 5 it is possible to observe that good agreement between numerical and experimental results was achieved by comparing the ultimate moment capacity $M_{u}$ and the displacement $\delta_{u}$ at $M_{u}$. Moreover, the mode of failure that involved the main spatial plastic mechanism of the top compression flange was well captured for both sections profiles, as illustrated in Figure 15a-d. Figure 15e-f show that web buckling was also well represented by the numerical models of RHFB-300 specimens. However, looking in detail at the mode of failures depicted in Figure 15g-h, the FE model of the RHFB-240 specimens was not capable of detecting some minor plasticization mechanisms occurred early in the tests. As stated above, these profiles were more affected by imperfections and by local effects owing to smaller thicknesses and the production process. This phenomenon determined an increase in deformability of the specimens that is shown by the difference in elastic branch behaviour between tests and numerical analyses, as illustrated in Figure 16a-c. This is more evident in T02 RHFB-240 and T03 RHFB-240, whilst for T01 RHFB-240 
the bending moment at which the formation of a minor plastic mechanism occurs, is delayed and clearly highlighted by sudden deviation from linear behaviour. Nevertheless, the ultimate values of RHFB-240 numerical analyses were not significantly affected. In RHFB-300 tests, early minor local plasticization was not detected, and the numerical elastic behaviour well agrees with the experimental one, as illustrated in Figure 16d-f.

Table 5. Comparison of the flexural behaviour between numerical and experimental results.

Figure 15. Comparison of the mode of failure: a) main plastic mechanism RHFB-240 test; b) main plastic mechanism RHFB-240 FE; c) main plastic mechanism RHFB-300 test; d) main plastic mechanism RHFB-300 FE; e) web buckling RHFB-300 test; f) web buckling RHFB-300 FE; g) plastic mechanisms in RHFB-240 test; h) plastic mechanisms in the RHFB-240 FE analysis.

Figure 16. Comparison of bending moment-displacement curves: a) T01 RHFB-240; b) T02 RHFB240; c) T03 RHFB-240; d) T04 RHFB-300; e) T05 RHFB-300; f) T06 RHFB-300.

\section{PARAMETRIC STUDIES}

In order to broaden the available findings over a wider slenderness range of the tubes composing the flanges, a series of parametric studies was conducted. Material properties representative of material coupon tests that include flexural residual stresses were used in the parametric analyses. Local geometric imperfections were modelled by means of the lowest buckling mode shape. The amplitude of local imperfections was introduced according to Eq. (1). No global geometric imperfections were included because global buckling was prevented. A 4-point bending scheme was used with span of the beams set to 
$4 \mathrm{~m}$ and a distance of $1 \mathrm{~m}$ between the point loads. The effect of the moment gradient was not investigated as it was found to be negligible with respect to moment capacity of carbon steel [27] and stainless steel flexural members [28]. The dimensions of the cross section were the ones of the T01 RHFB-240 profile and the T04 RHFB-300 profile but the thickness, that was varied between $1.2 \mathrm{~mm}$ and $4 \mathrm{~mm}$ for the RHFB-240 profile and between $1.8 \mathrm{~mm}$ and $5 \mathrm{~mm}$ for the RHFB-300 cross section, respectively. The limit of a Class 3 section according to the EN1993-1-1 [19] was assessed by plotting the normalised ultimate moment $M_{u}$ over the elastic bending moment $M_{y}$ with respect to the most limiting $c / t \varepsilon$ slenderness value that was the tube flange in compression, where $c$ is the flat width of the plate element, $t$ its thickness and $\varepsilon=\sqrt{ }\left(235 / f_{y}\right) . M_{y}=M_{y . f}$, as described in Section 4, was employed. As expected, the parametric study showed no considerable difference between the two cross sections owing to geometry similarity normalised with respect to the material strength. In fact, from Figure 17 it is possible to observe that trend line obtained through linear regression has same slope and intercept values. From Figure 17 it is possible to note that EN1993 tends to be conservative by underestimating the flexural capacity of RHFB cross-sections. The Class 3 limit is also conservative: from the parametric analyses the onset of local buckling of the tube flange in compression, i.e. when $M_{u} / M_{y}<1$, is observed for $c / t \varepsilon$ equal to about 48 instead of 42 . Nevertheless, the EN1993 prediction exhibits a $M_{u} / M_{y}$ vs. c/tE evolution that follows well the trend of FE results.

Figure 17. Parametric analysis: a) RHFB-240; b) RHFB-300.

Furthermore, the capability of the DSM [2] to predict the flexural behaviour of RHFBs was investigated. The main idea behind this method is the determination of all elastic 
instabilities, i.e. local $M_{\text {cre }}$, distortional $M_{\text {crd, }}$ global buckling $M_{\text {cre }}$ and the bending moment that causes yield, i.e. $M_{y}$. The smallest moment among $M_{\text {cre }}, M_{\text {crd }}, M_{c r e}$ and $M_{y}$ identifies the bending resistance of the section. Since lateral-torsional buckling and lateral-distortional buckling do not apply to the case study, only local buckling is considered, as illustrated in the finite strip solution depicted in Figure 18 [29]. It is worth to point out that for comparison purposes input data of finite strip analyses in terms of geometry of the cross section and mechanical properties, i.e. yield strength, elastic modulus and Poisson's coefficient, were chosen consistently with the FE analyses. The stress distribution was assumed according to the $M_{y . f .}$ No imperfections were included and bending resistance beyond the elastic bending moment is not estimated. Thus, it is interesting to observe when local buckling becomes significant and affects the flexural strength of the beam by preventing the attainment of the elastic bending moment. Figure $17 a$ and $b$ show that the DSM provides a good prediction for $c / t \varepsilon$ slenderness value up to 55 , then it tends to significantly underestimate the flexural strength $(c / t \varepsilon>60)$.

Figure 18. Finite strip analysis of a RHFB-240 profile with thickness equal to $1.4 \mathrm{~mm}$.

\section{CONCLUSIONS}

The article reported the results of a comprehensive experimental-numerical study on coldformed laterally-restrained steel rectangular hollow flanges beams (RHFBs) that was carried out in order to investigate their flexural capacity. The behaviour of RHFB-300 specimens was influenced by a significant difference in yield strength between the tubes and the web that induced local buckling and plastic behaviour in the web. All experimental 
tests showed well-distributed local buckling waves on the compression top flange. Some minor plasticization was observed outside the zone between the point loads owing to local imperfections associated with still significant bending moment close to the constant bending moment region. Furthermore, the RHFB-240 profiles exhibited minor plasticization, that caused an early loss of stiffness, prematurely in the tests because more prone to be affected by local imperfections and by local effects that were emphasized by a lack of optimisation in the way of production. In this respect, in order to reduce imperfections a more systematic production process with a dedicated cut machine is recommended. Along this line, the insertion of an intermediate stiffener in the external plates of the hollow flanges is beneficial for increasing the local buckling critical load of the plate. Nevertheless, the exploitation of such profiles can be attractive for structural applications as secondary beams in small-framed houses because of favourable flexural performance/weight ratio.

Calibration of the numerical model provided good agreement with experimental tests in terms of ultimate bending moment, ultimate displacement, mode of failure. The initial elastic stiffness was well reproduced in RHFB-300 beams whereas the FE was not capable of detecting some minor plasticization occurred early in the RHFB-240 specimen tests owing to local imperfections and local effects. Parametric analyses showed that both EN1993 and DSM tend to be conservative in predicting the section bending capacity of RHFB profiles. Nonetheless, the EN1993 prediction exhibits a $M_{u} / M_{y}$ vs $c / t \varepsilon$ evolution that follows well the trend provided by the FE results whereas DSM provides a good prediction for $c / t \varepsilon$ slenderness value up to 55 , then it tends to significantly underestimate the flexural capacity of RHFB for high slenderness ratios $(c / t \varepsilon>60)$ of the tube compression flange. 


\section{ACKNOWLEDGEMENTS}

Dr. N. Tondini and the experimental programme have been supported by the Province of Trento through the Call 3 - post-doc 2009 (Outgoing) - FIRAS project, which is gratefully acknowledged. The steelwork company Gruppo Manni and in particular Eng. Adolfo Bozzoli are also gratefully acknowledged.

\section{REFERENCES}

[1] Hancock GJ, Cold-formed steel structures; Journal of Constructional Steel Research 2003; 59:473-487.

[2] Schafer BW. Review: The Direct Strength Method of cold-formed steel member design; Journal of Constructional Steel Research 2008; 64:766-778.

[3] Li Z, Batista Abreu JC, Leng J, Ádány S, Schafer BW. Review: Constrained finite strip method developments and applications in cold-formed steel design, Thin-Walled Structures $2014 ; 81: 2-18$.

[4] Lee YH, Tan CS, Mohammad S, Tahir MM, Shek PN. Review on Cold-Formed Steel Connections, The Scientific World Journal 2014; 1-11.

[5] Wang L, Young B. Design of cold-formed steel channels with stiffened webs subjected to bending, Thin-Walled Structures 2014; 85:81-92.

[6] Mahendran M, Keerthan P, Experimental studies of the shear behavior and strength of LiteSteel beams with stiffened web openings, Engineering Structures 2013; 49:840-854.

[7] Anapayan T, Mahendran M. Improved design rules for hollow flange sections subject to lateral distortional buckling, Thin-Walled Structures 2012; 50:128-140.

[8] Anapayan T, Mahendran M, Mahaarachchi D. Section moment capacity tests of LiteSteel beams, Thin-Walled Structures 2011, 49:502-512. 
[9] Anapayan T, Mahendran M, Mahaarachchi D. Lateral distortional buckling tests of a new hollow flange channel beam, Thin-Walled Structures 2011, 49:13-25.

[10] Kurniawan CW, Mahendran M. Elastic lateral buckling of simply supported Lite Steel beams subject to transverse loading, Thin-Walled Structures 2009, 47:109-119.

[11] Avery, P., Mahendran, M. Finite-element analysis of hollow flange beams with web stiffeners, Journal of Structural Engineering 1997; 123(9):1123-1129.

[12] Mahendran M, Avery P. Buckling experiments on hollow flange beams with web stiffeners, Journal of Structural Engineering 1997; 123(9): 1130-1134.

[13] Avery P, Mahendran M, Nasir A. Flexural capacity of hollow flange beams, Journal of Constructional Steel Research 2000; 53:201-223.

[14] Hassanein MF, Kharoob OF, El Hadidy AM. Lateral-torsional buckling of hollow tubular flange plate girders with slender stiffened webs, Thin-Walled Structures 2013, 65:49-61.

[15] Hassanein MF, Kharoob OF. Shear capacity of stiffened plate girders with compression tubular flanges and slender webs, Thin-Walled Structures 2013, 70:81-92.

[16] Hassanein MF, Kharoob OF. Flexural strength of hollow tubular flange plate girders with slender stiffened webs under mid-span concentrated loads, Thin-Walled Structures 2013, 69:18-28.

[17] Hassanein MF, Silvestre N. Lateral-distortional buckling of hollow tubular flange plate girders with slender unstiffened webs, Engineering Structures 2013, 56:572-584.

[18] Hassanein MF. Shear strength of tubular flange plate girders with square web openings, Engineering Structures 2014, 58:92-104.

[19] EN1993-1-1. Eurocode 3 Design of steel structures Part 1-1: General rules and rules for buildings, Bruxelles: CEN; 2005.

[20] EN ISO 6892-1. Metallic materials - Tensile testing - Part 1: Method of test at room temperature, Bruxelles: CEN; 2009. 
[21] EN10025-2. Hot rolled products of structural steels - Part 2: Technical delivery conditions for non-alloy structural steels, Bruxelles: CEN; 2005.

[22] Schafer BW, Peköz T. Computational modelling of cold-formed steel: characterizing geometric imperfections and residual stresses. Journal of Constructional Steel Research $1998,47: 193-210$.

[23] EN1993-1-3. Eurocode 3 - Design of steel structures - Part 1-3: General rules Supplementary rules for cold-formed members and sheeting, Bruxelles: CEN; 2006.

[24] EN1993-1-5. Eurocode 3 - Design of steel structures - Part 1-5: Plated structural elements, Bruxelles: CEN; 2006.

[25] ANSYS. Documentation for ANSYS - Release 14.0. Copyright SAS IP, Inc., 2011.

[26] Shifferaw Y, Schafer BW. Inelastic Bending Capacity of Cold-Formed Steel Members, Journal of Structural Engineering 2012; 138(4):468-480.

[27] Kuhlmann U. Definition of flange slenderness limits on the basis of rotation capacity values. Journal of Constructional Steel Research 1989; 14(1):21-40.

[28] Theofanous M, Gardner L. Experimental and numerical studies of lean duplex stainless steel beams. Journal of Constructional Steel Research 2010; 66:816-825.

[29] Li Z, Schafer B W. Buckling analysis of cold-formed steel members with general boundary conditions using CUFSM: conventional and constrained finite strip methods. Proceedings of the 20th International conference: Special Conference on Cold-Formed Steel Structures (St. Louis); 2010. 
Figure 1

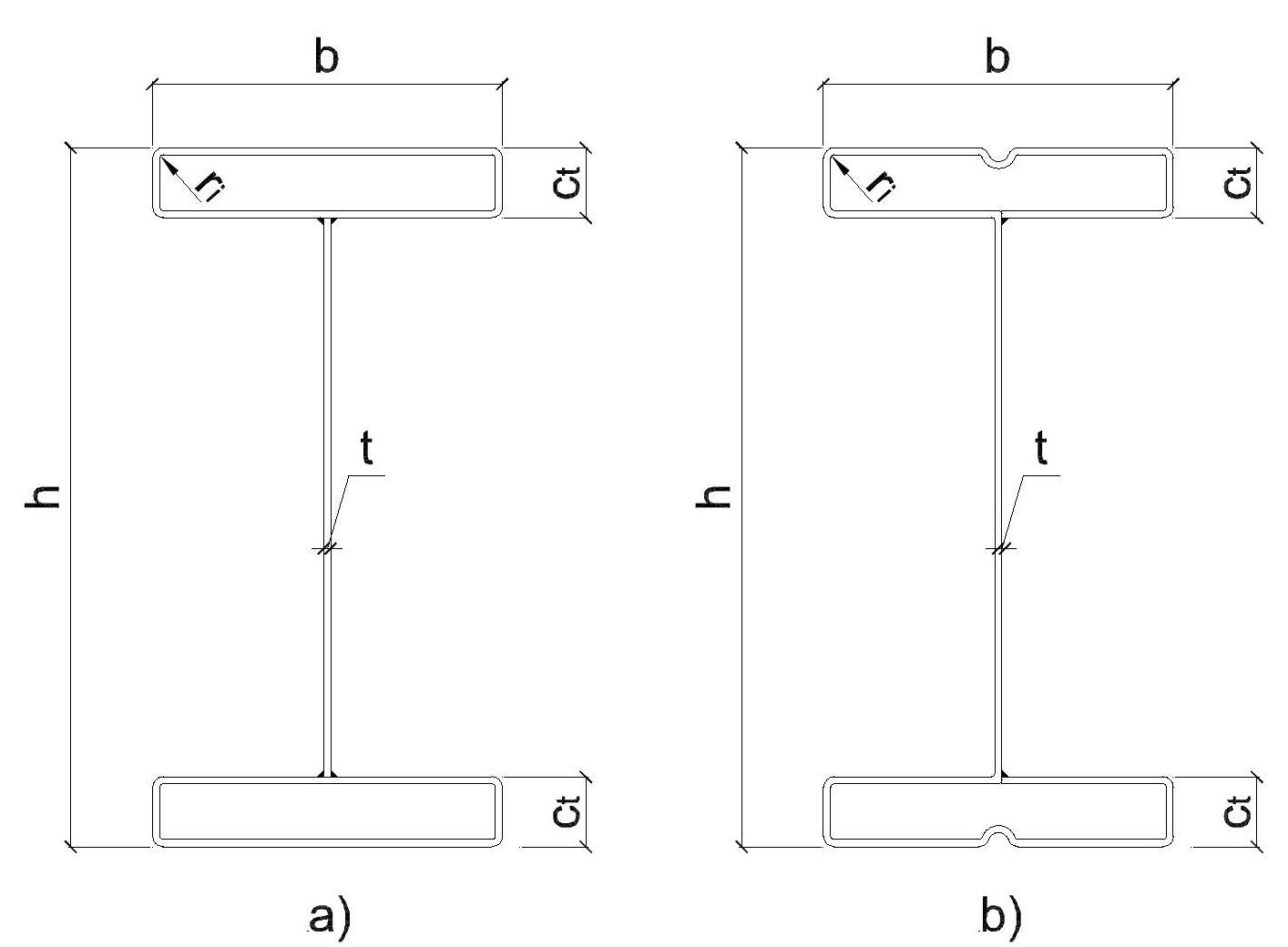

b)$$
\text { b) }
$$

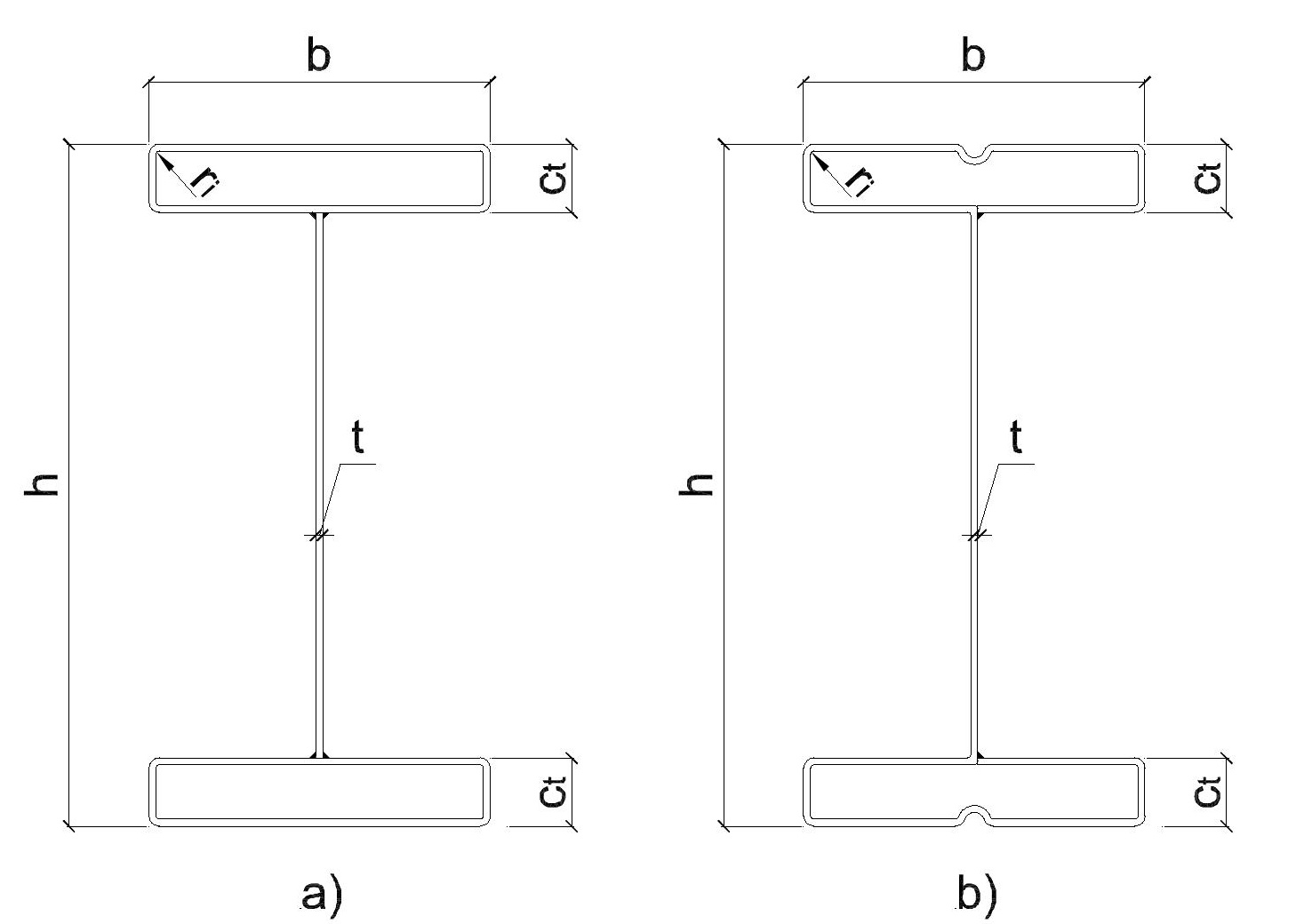

a)

a)

a)

\section{Figure 1}

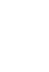


Click here to download high resolution image

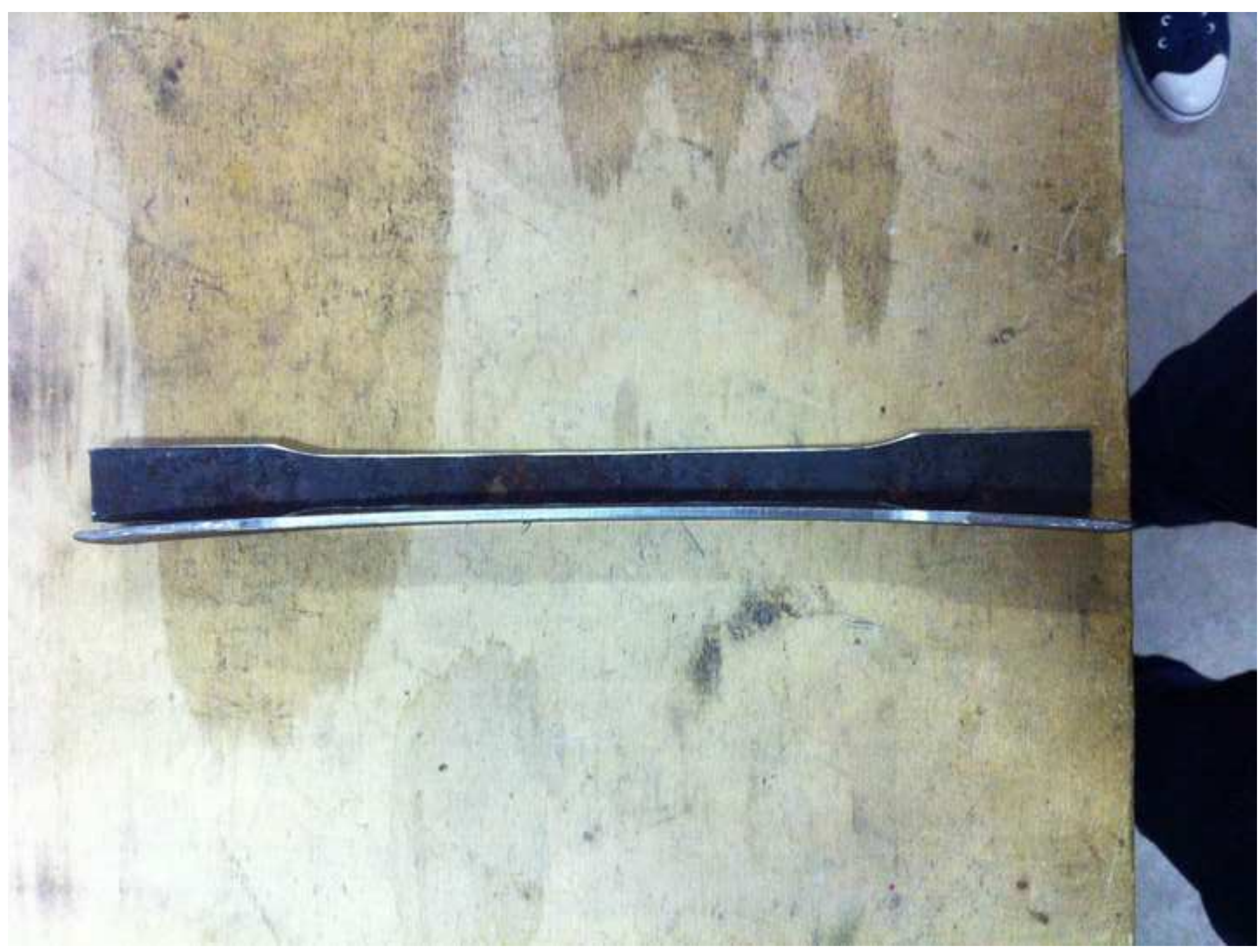




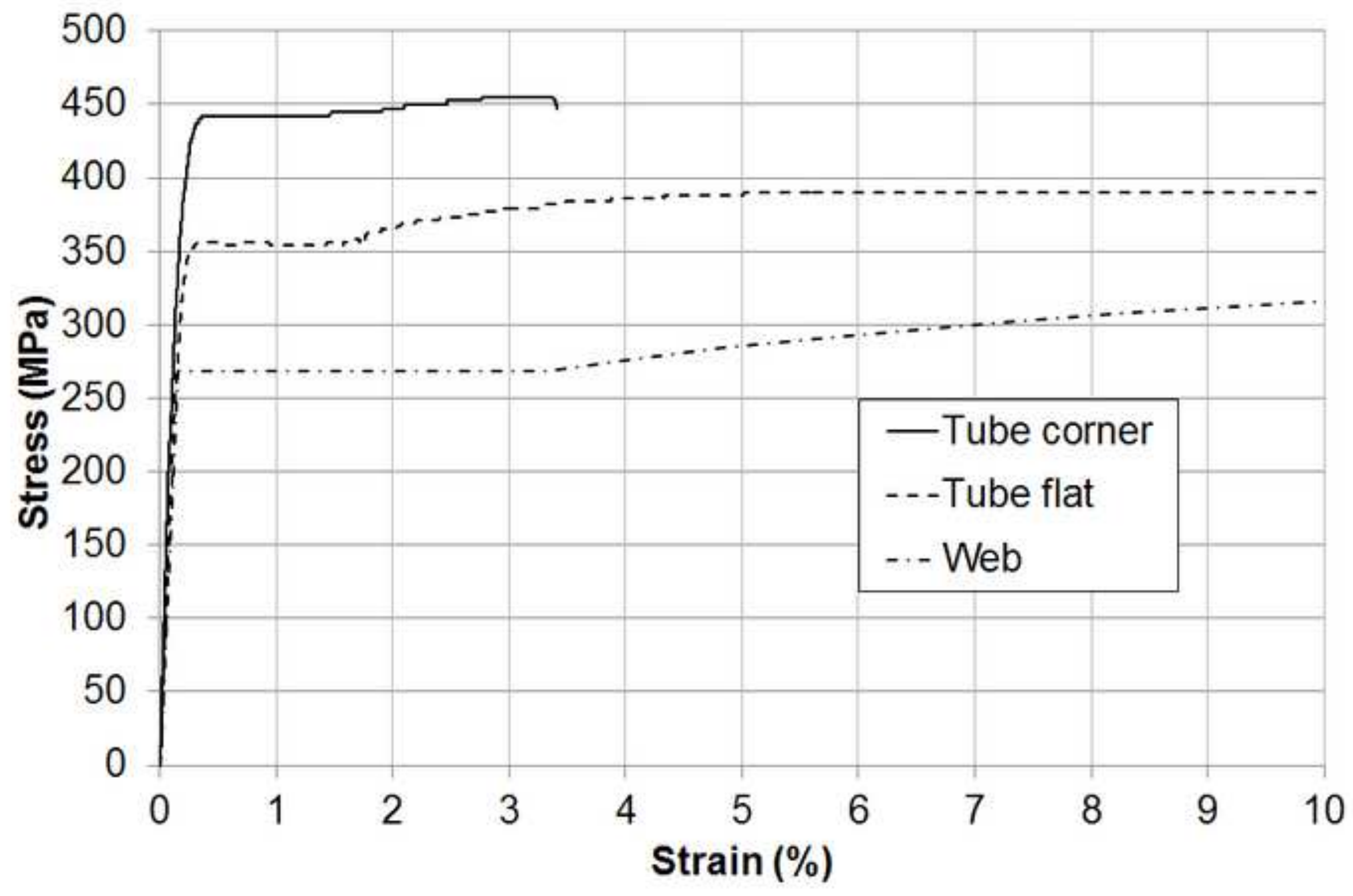




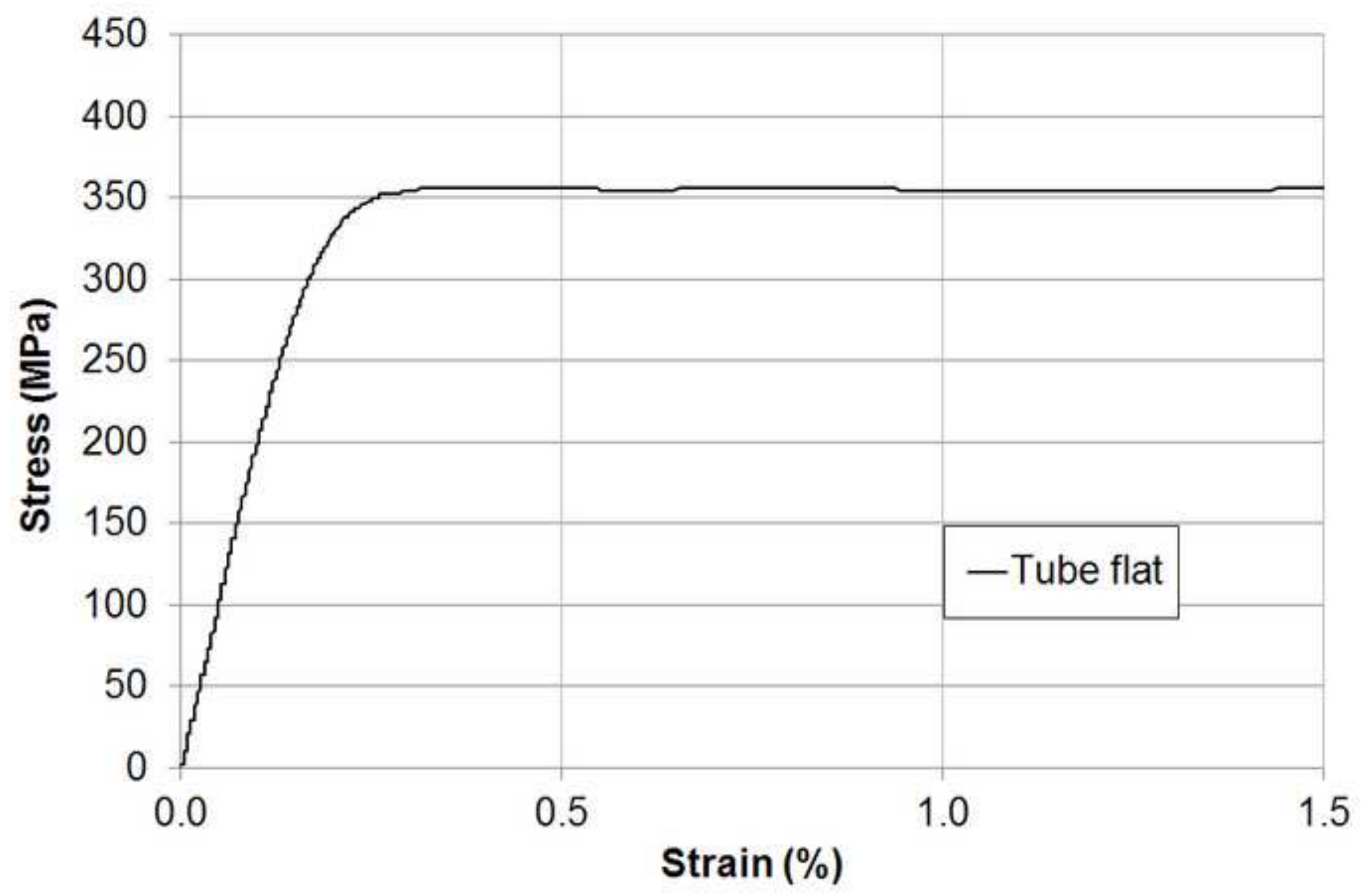


Figure 4a

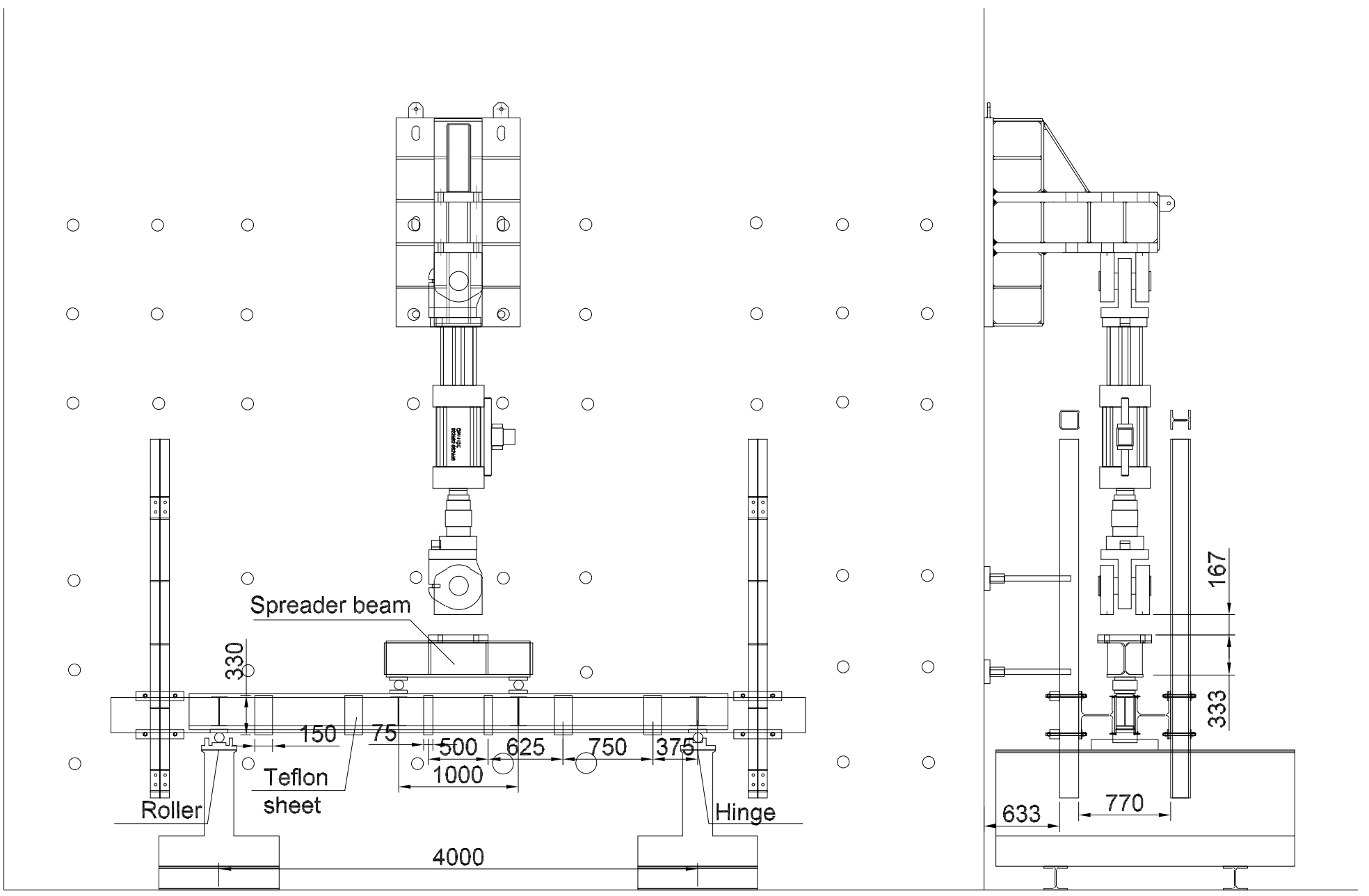

0

0

車

Roller
${ }^{\circ}$ Teflo sheet
○
$0 \longdiv { 0 0 } 0$ 


\section{Click here to download high resolution image}

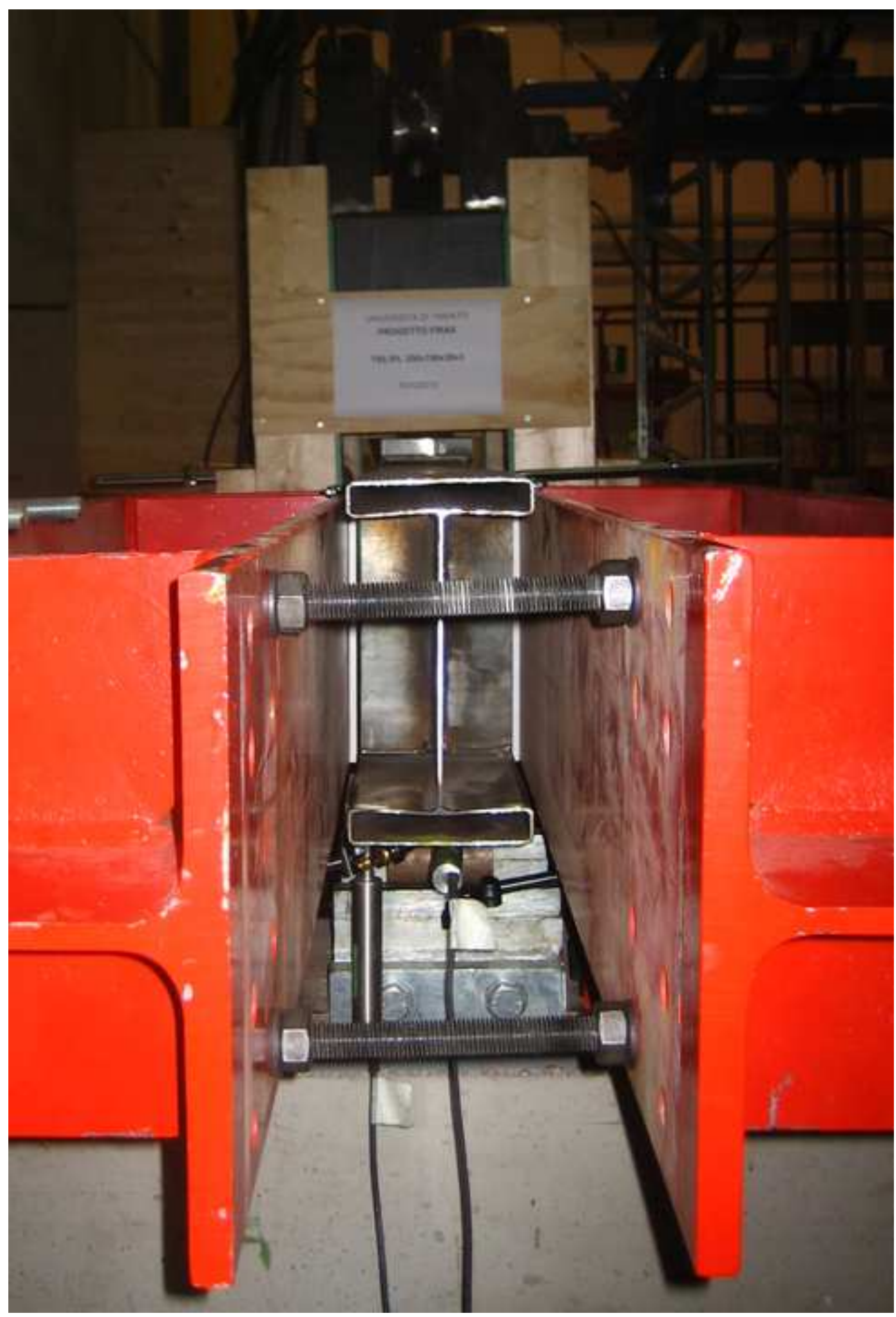


Click here to download high resolution image

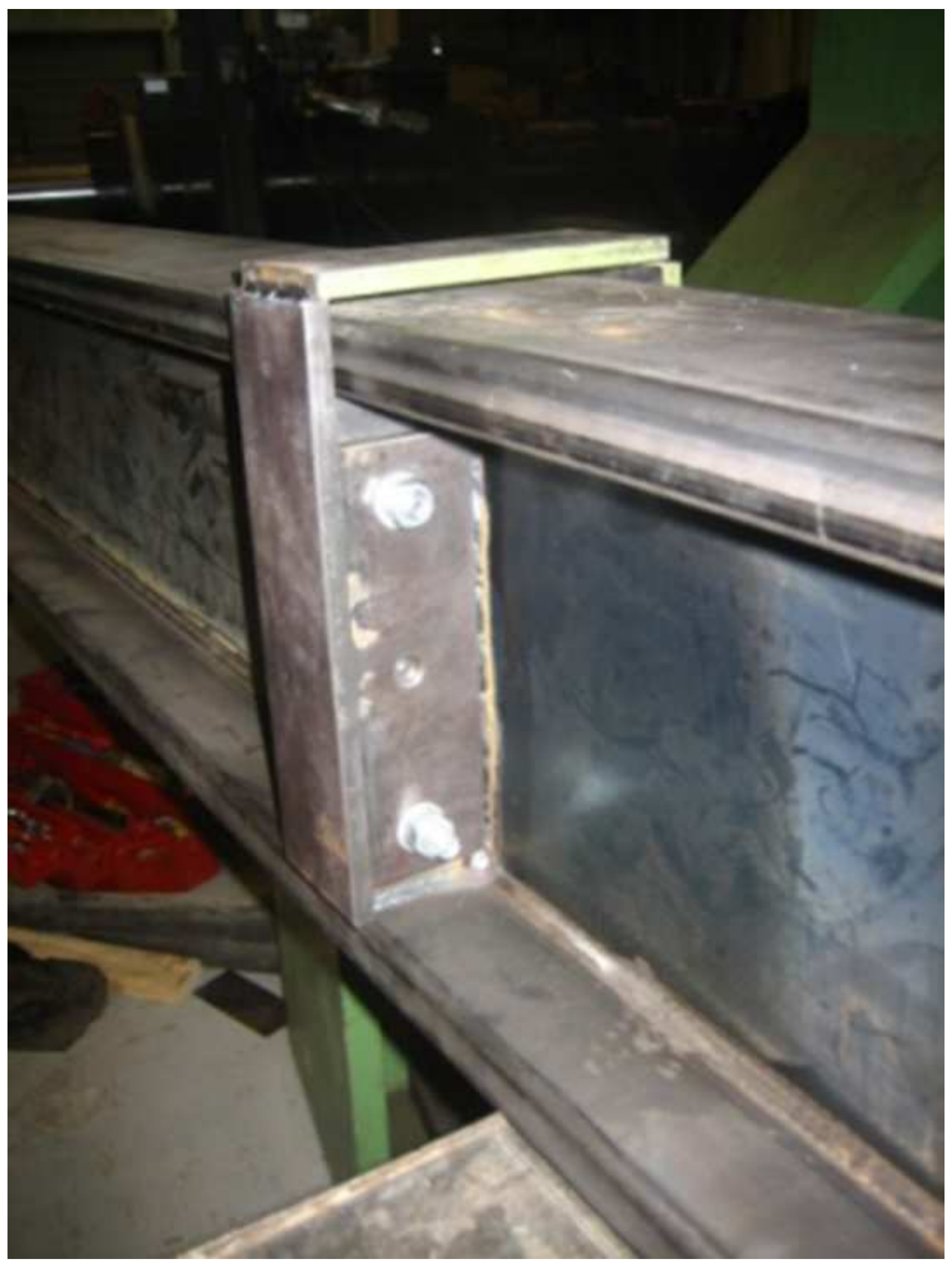




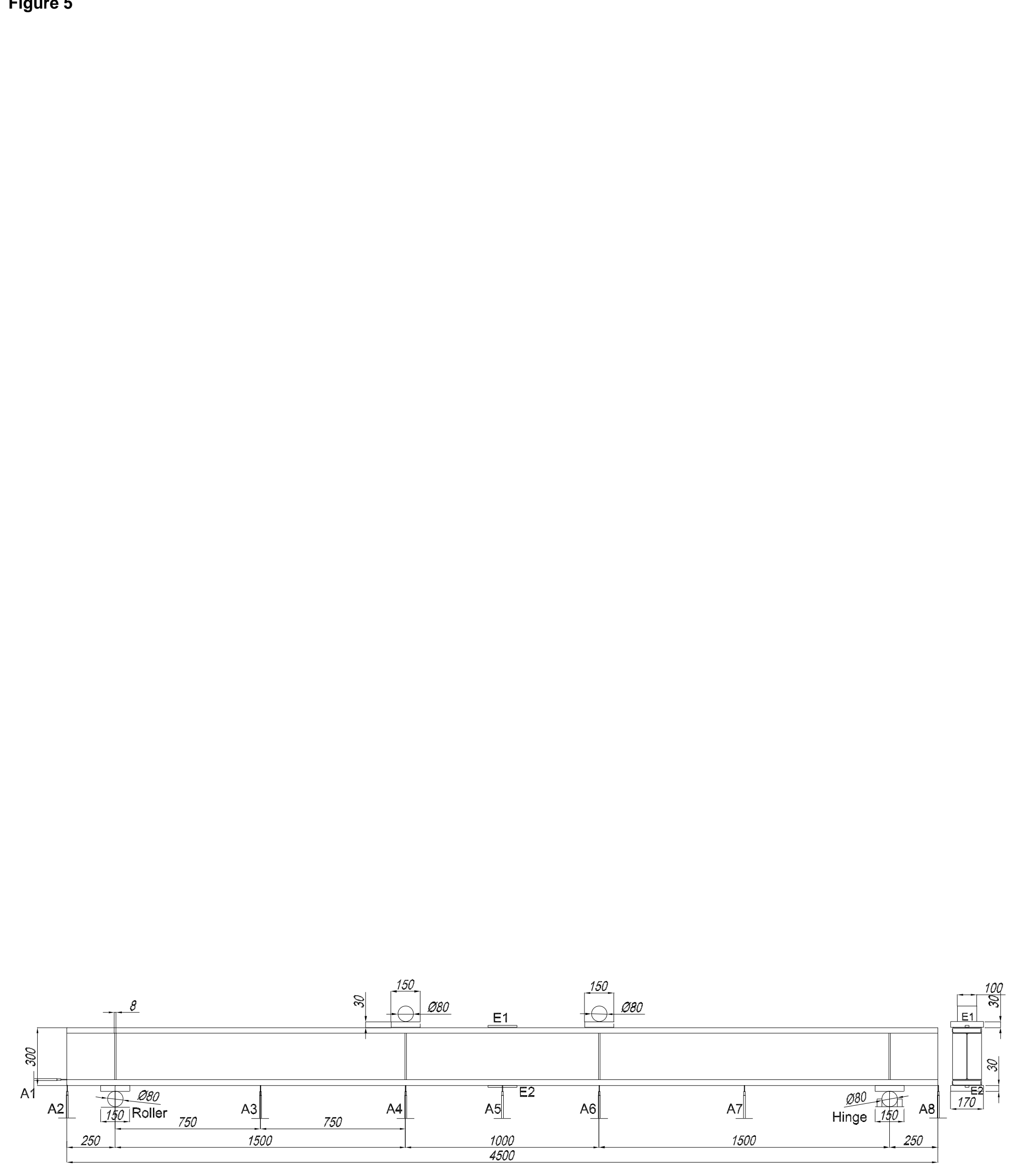

Figure 5

450
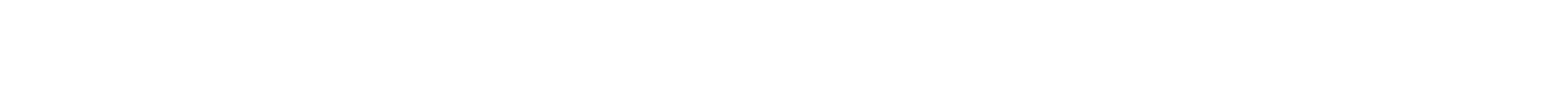

-

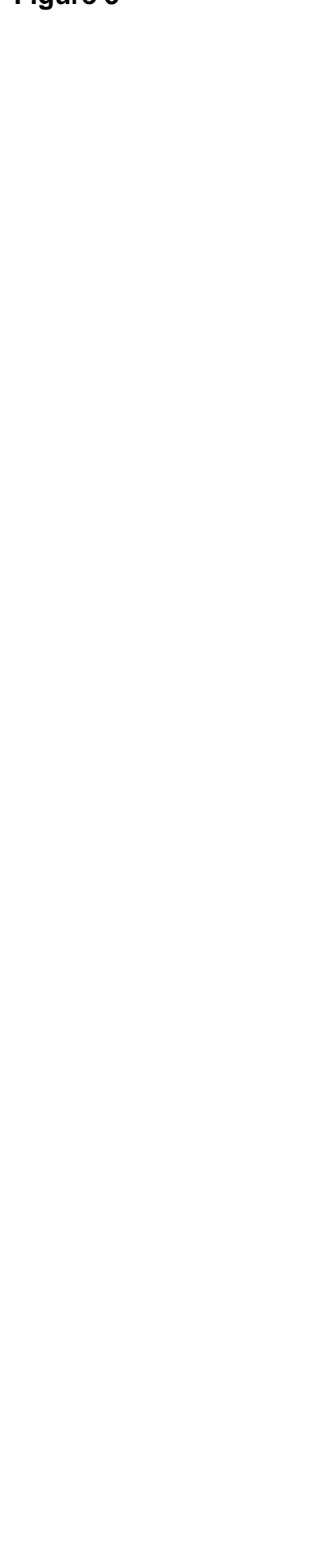


Figure $6 a$
Click here to download high resolution image

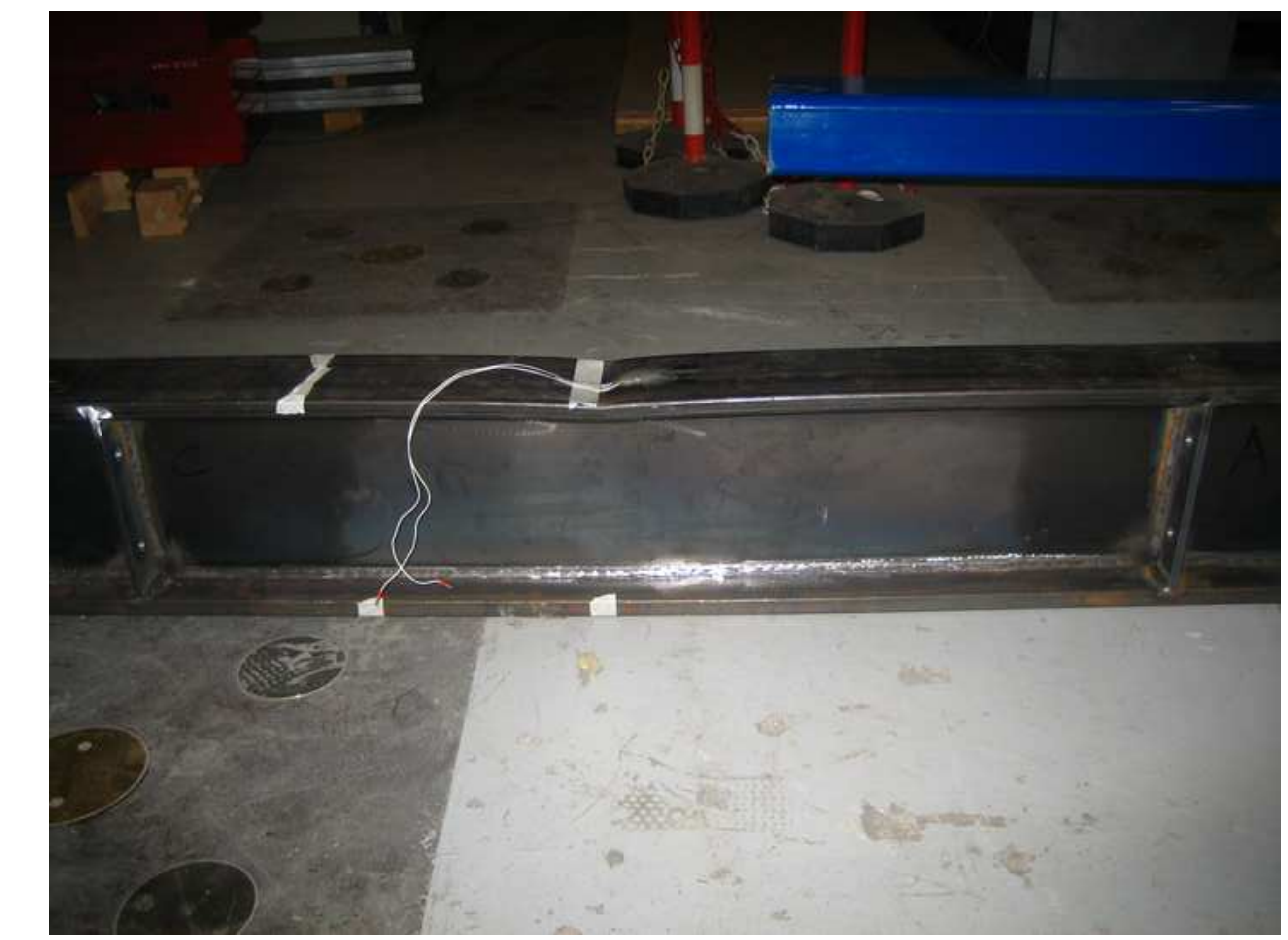


Figure $6 b$
Click here to download high resolution image
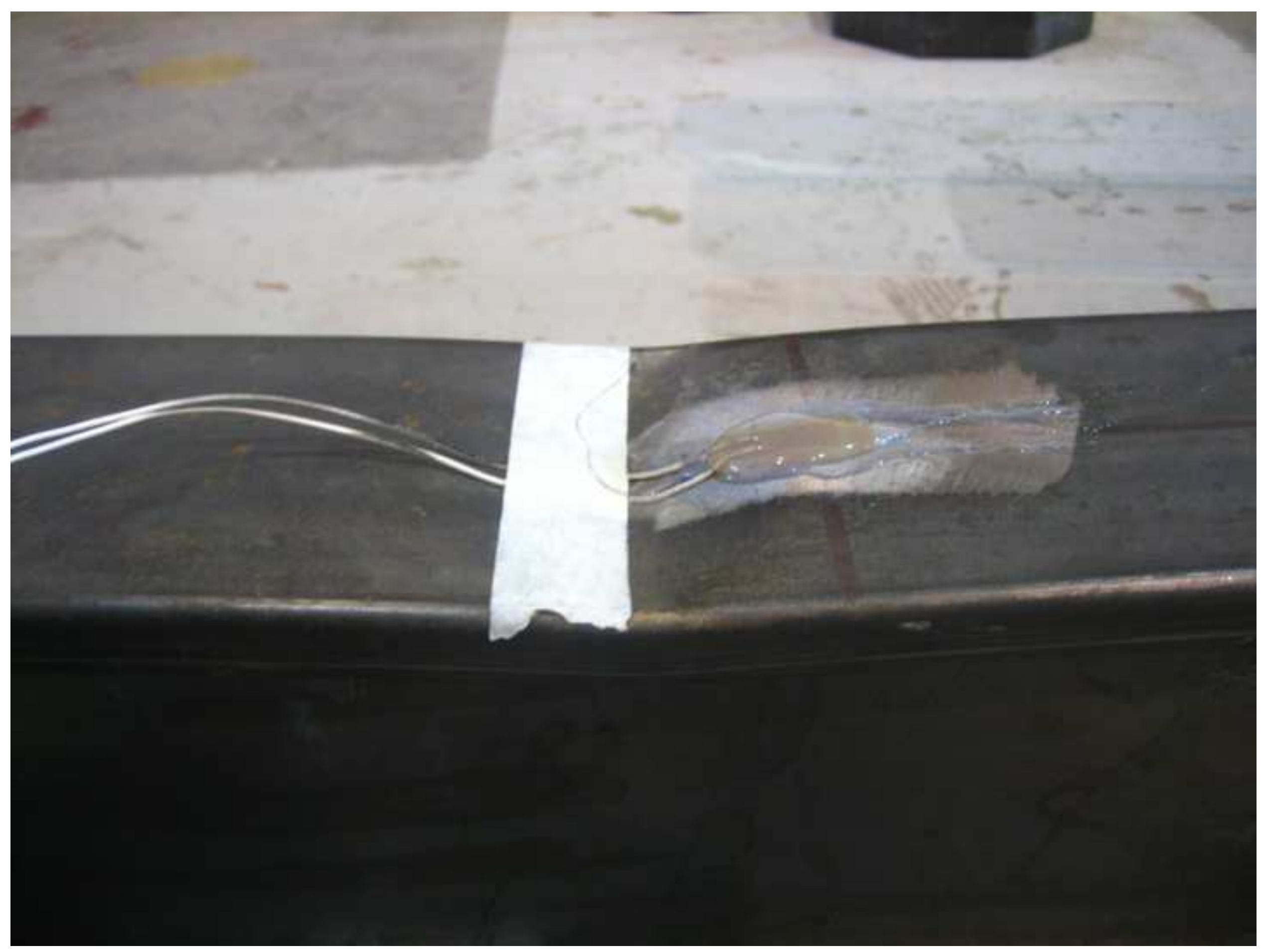
Click here to download high resolution image

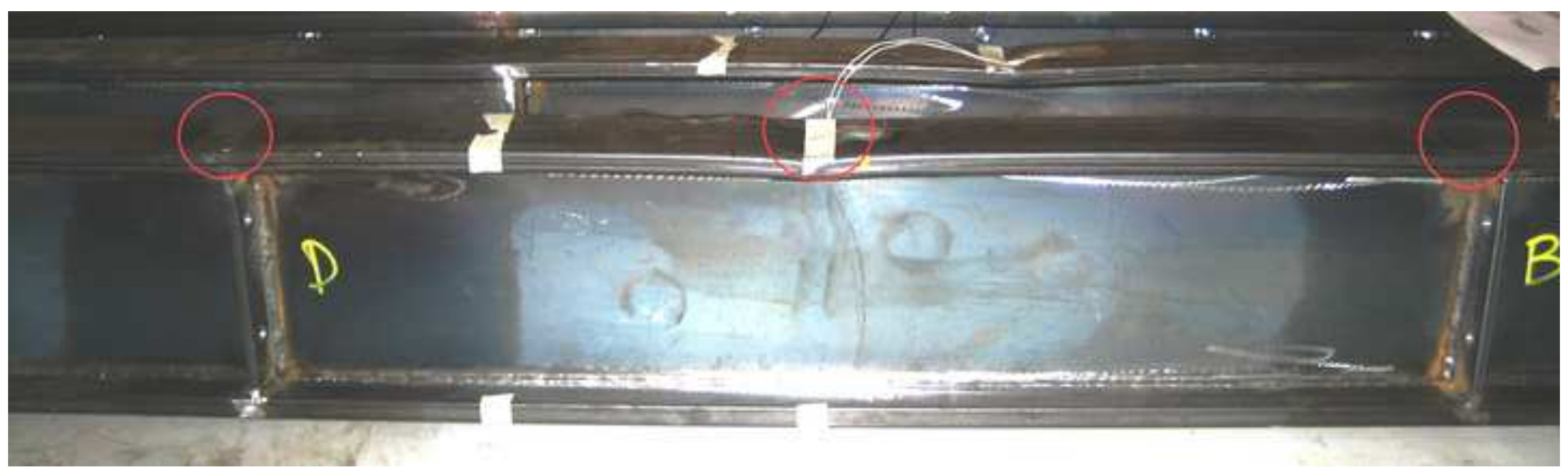


Click here to download high resolution image

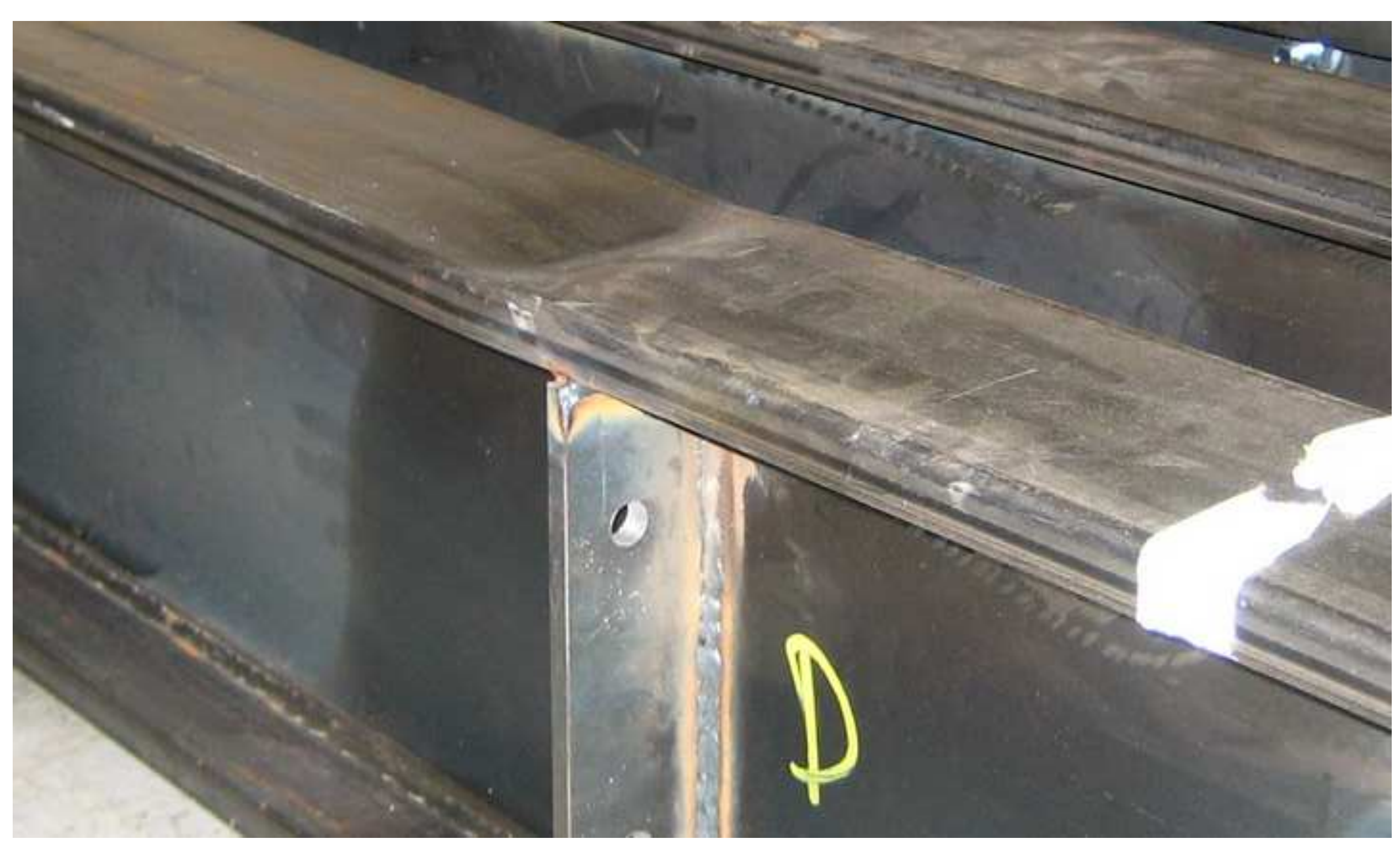

Clck here to download high resolu 
Click here to download high resolution image

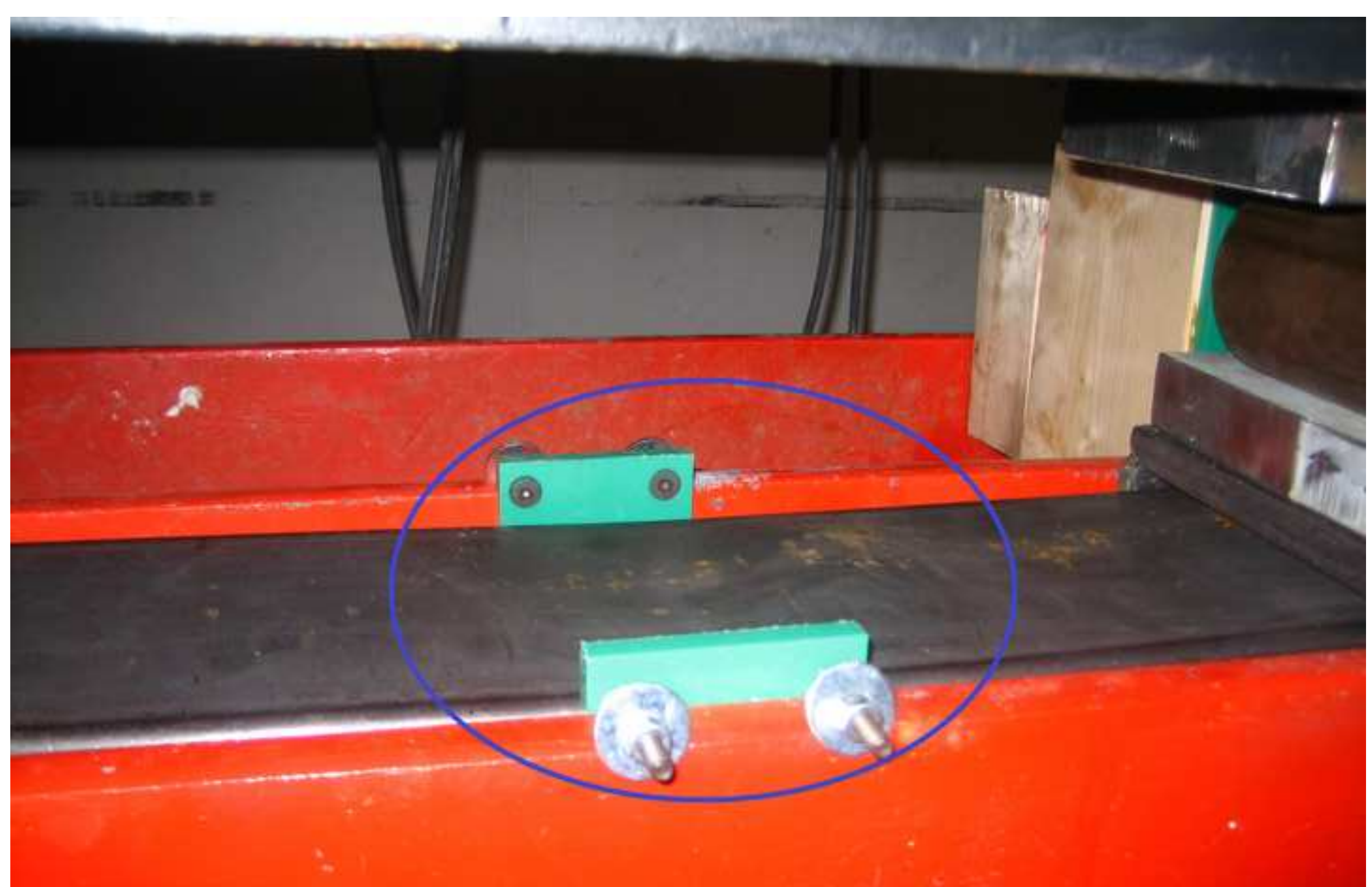




\section{Figure 7c}

Click here to download high resolution image

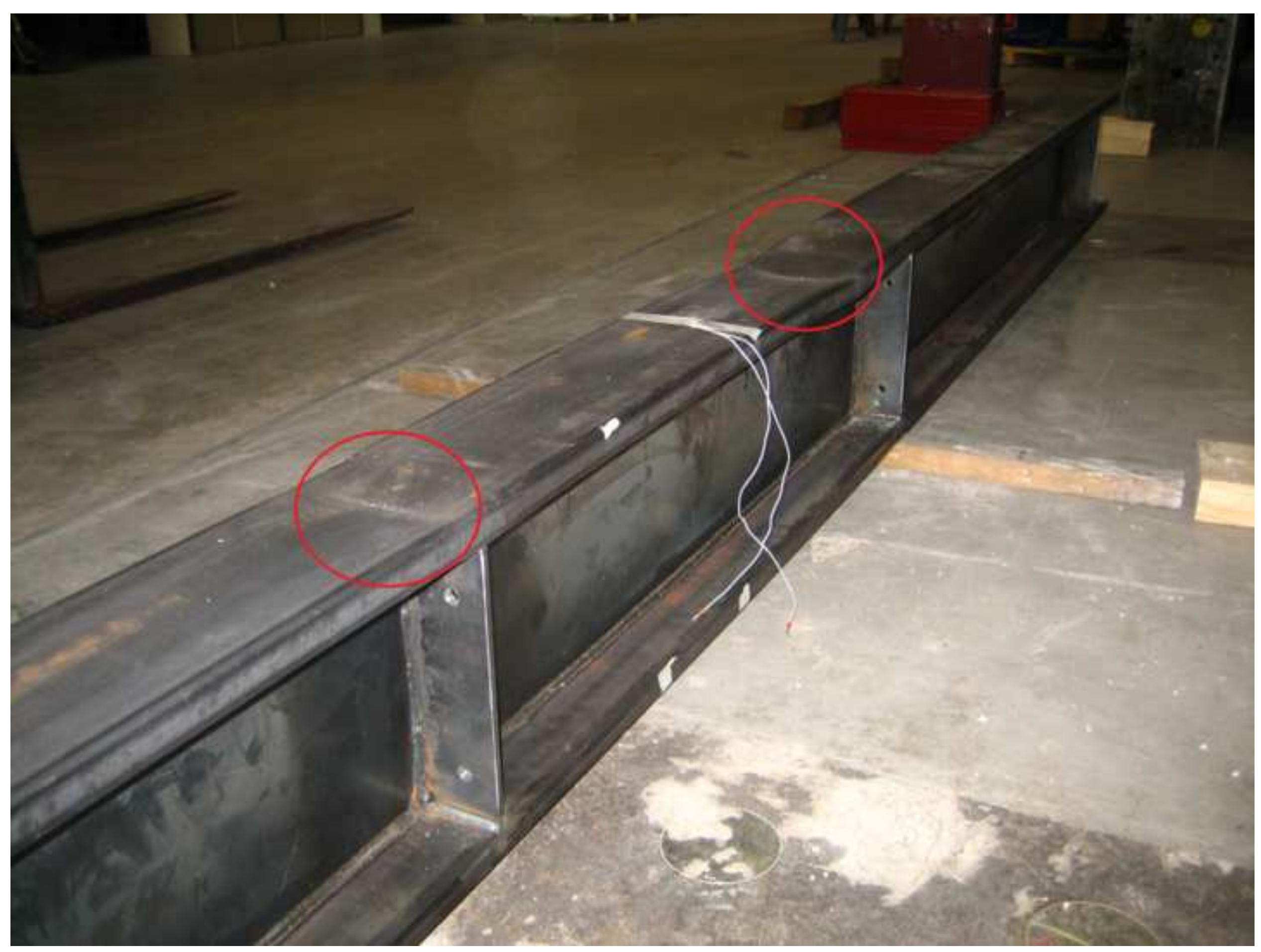


Click here to download high resolution image

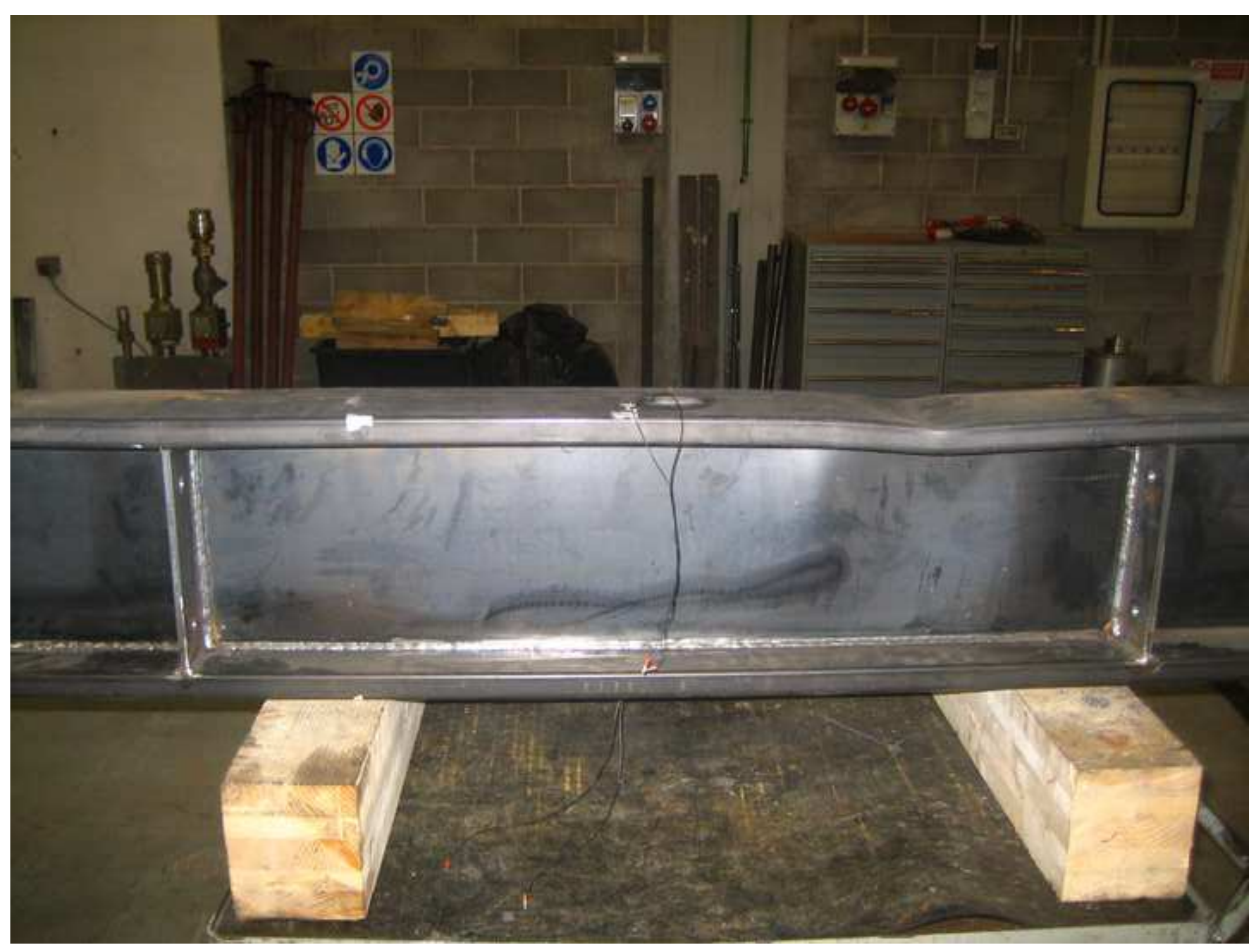




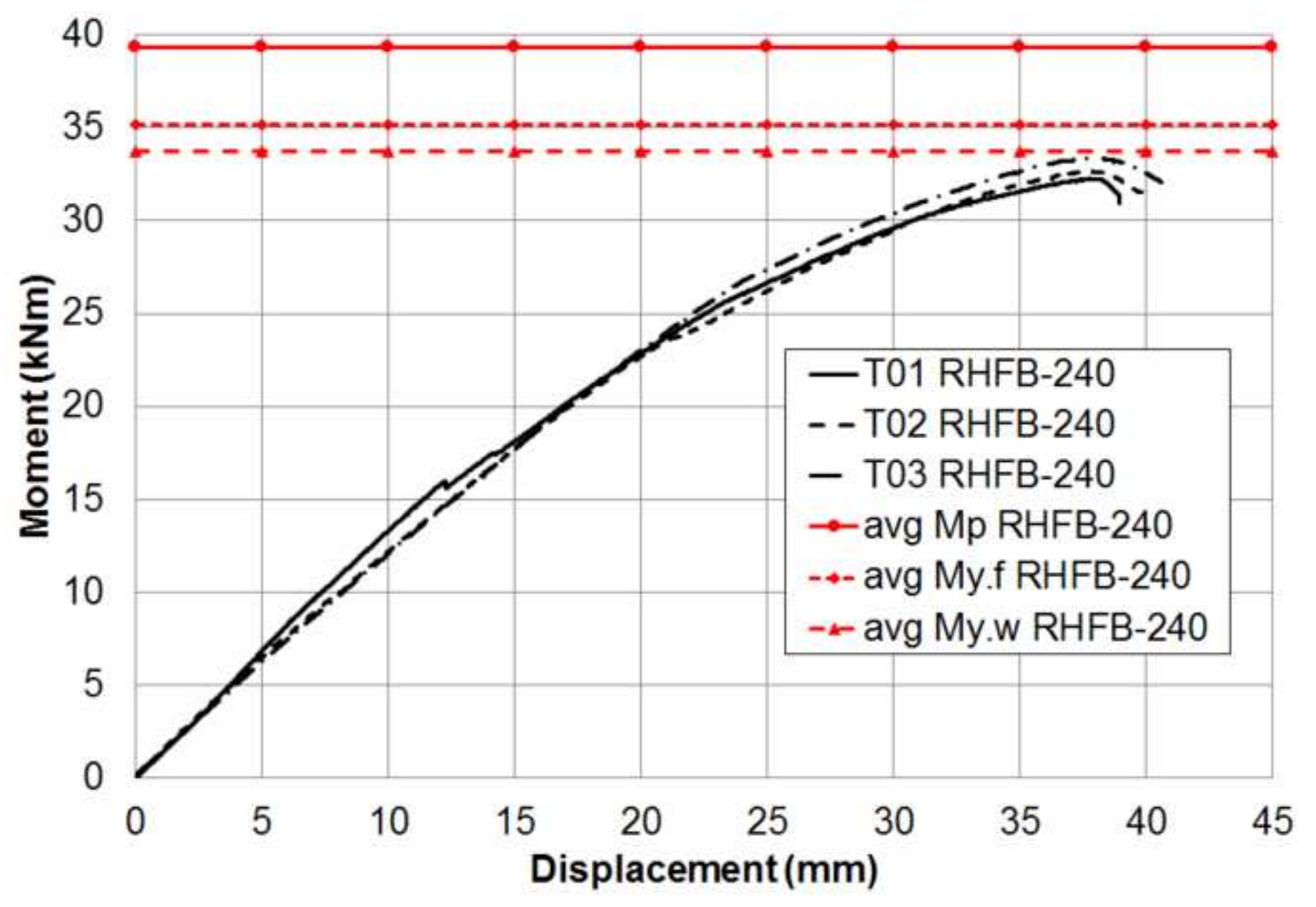


Figure 10
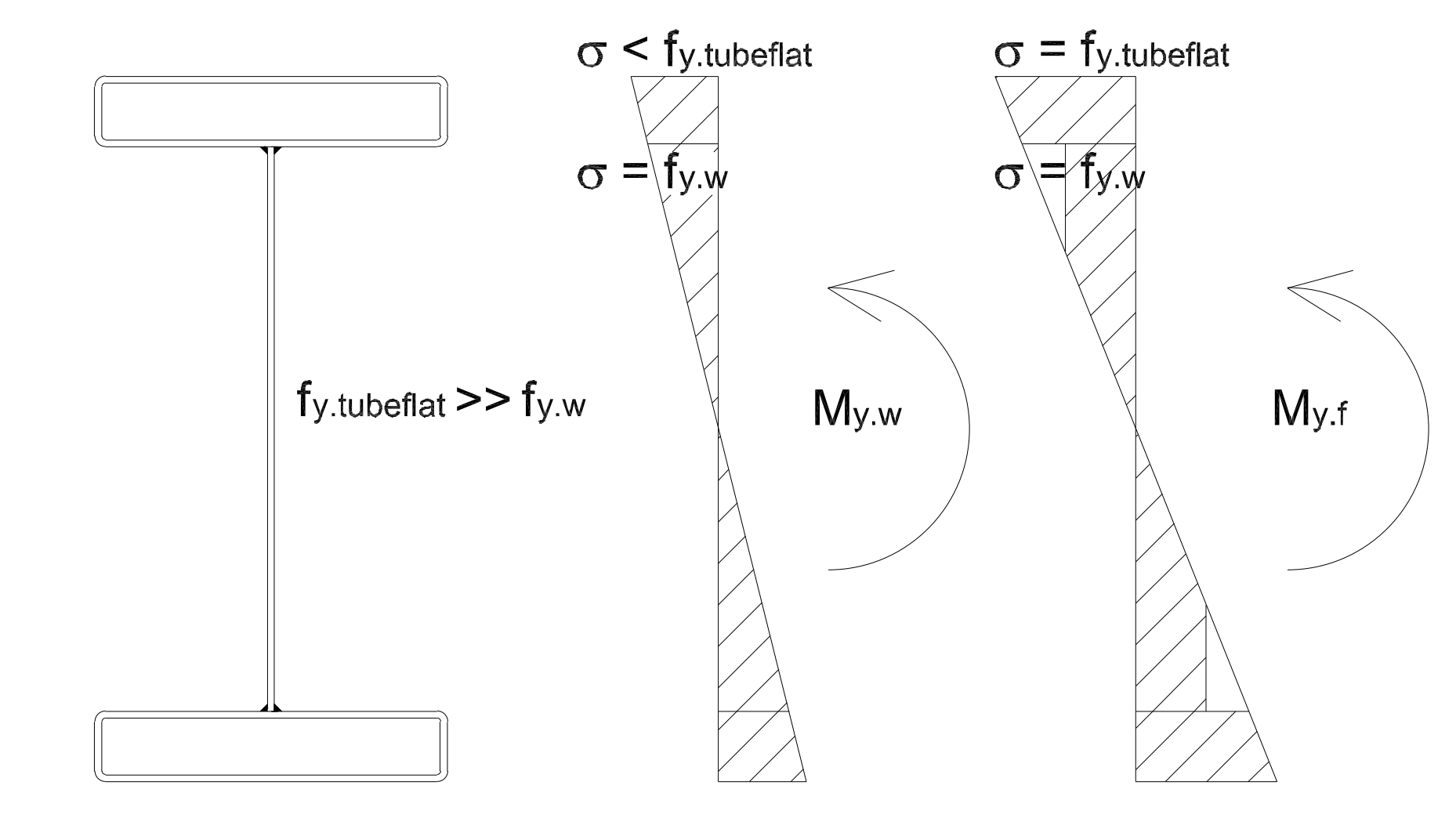

\section{Figure 10} fy.t

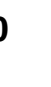

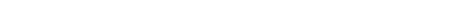

$$
\begin{aligned}
& \text { a }=0
\end{aligned}
$$

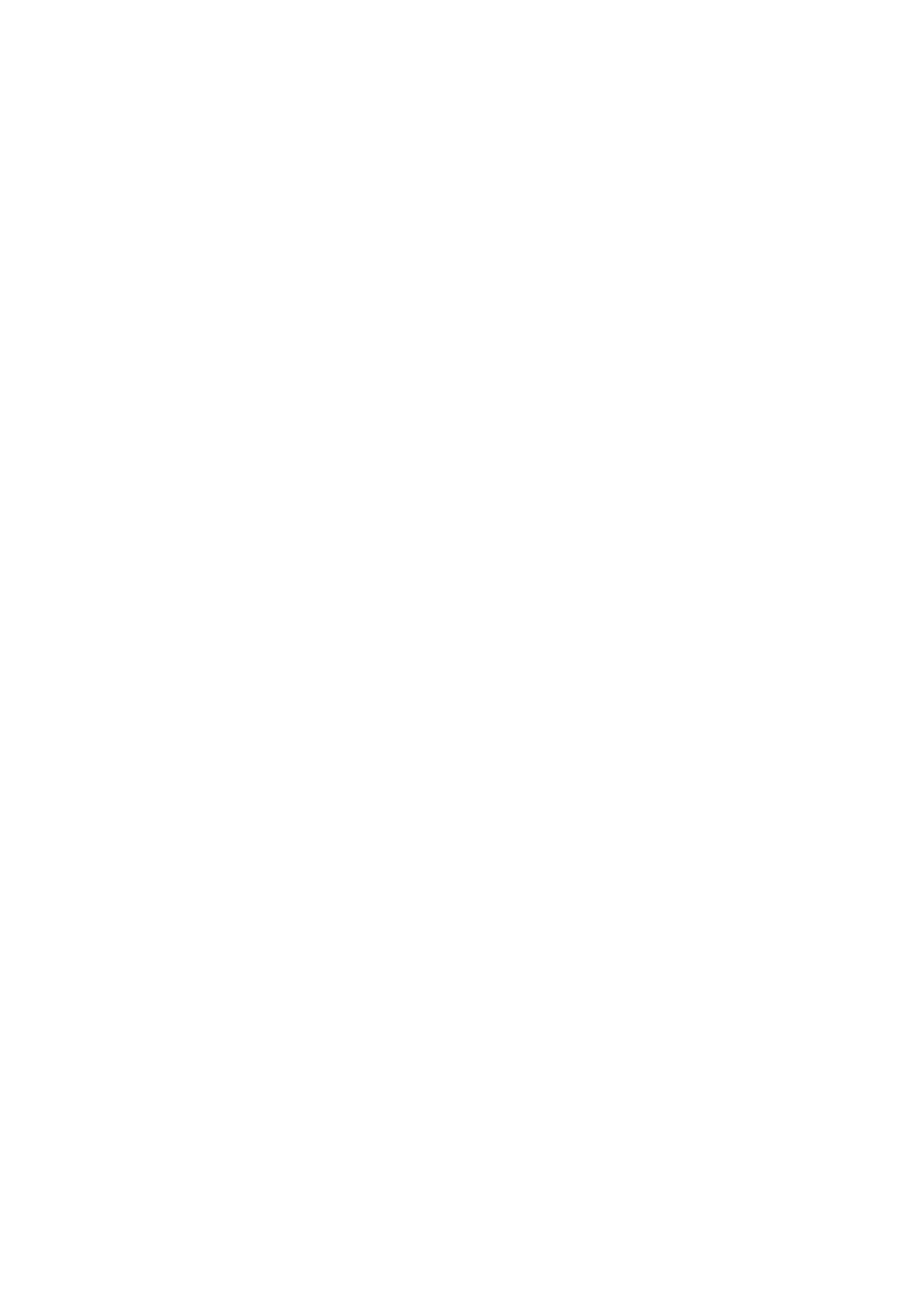




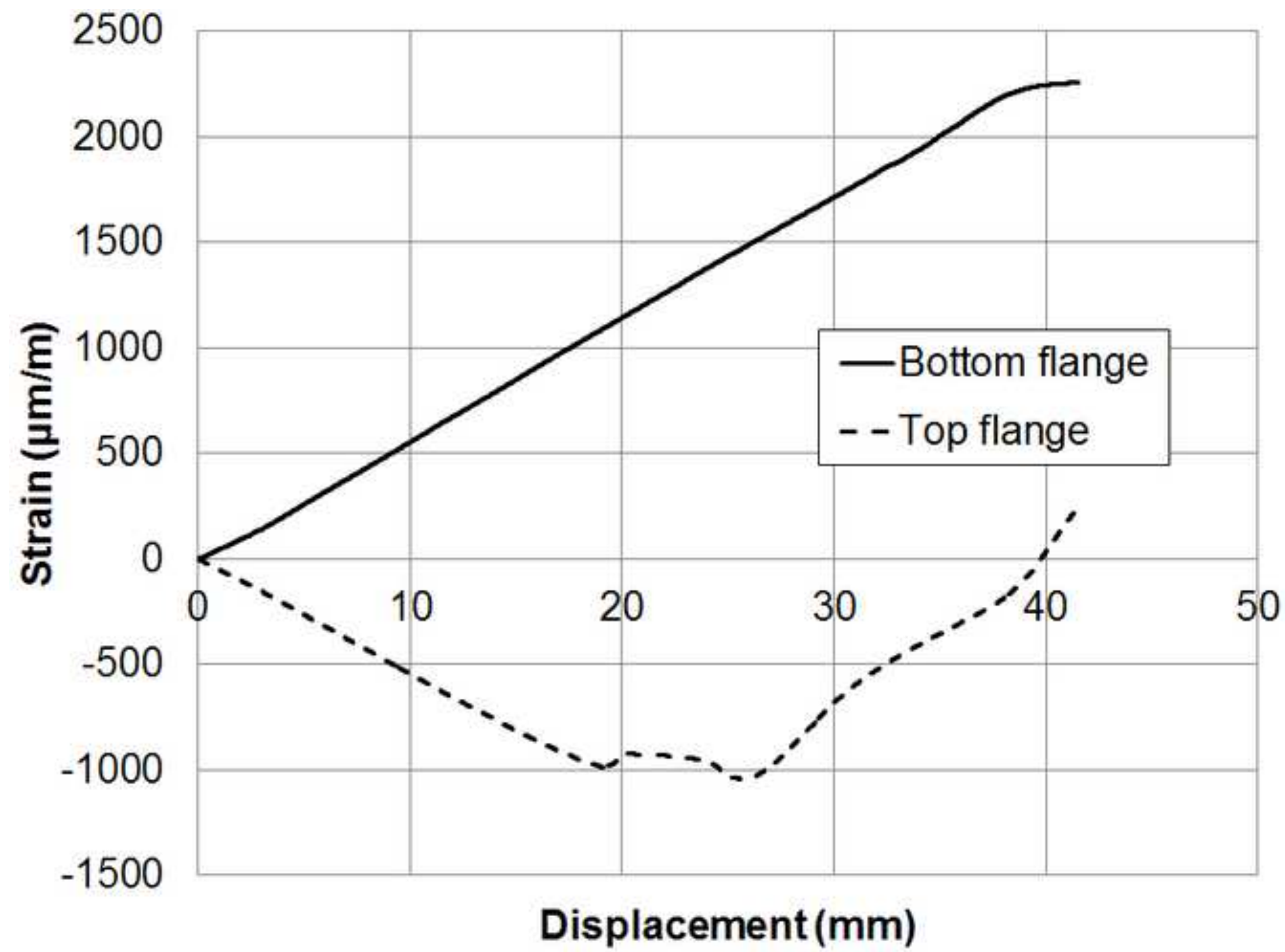




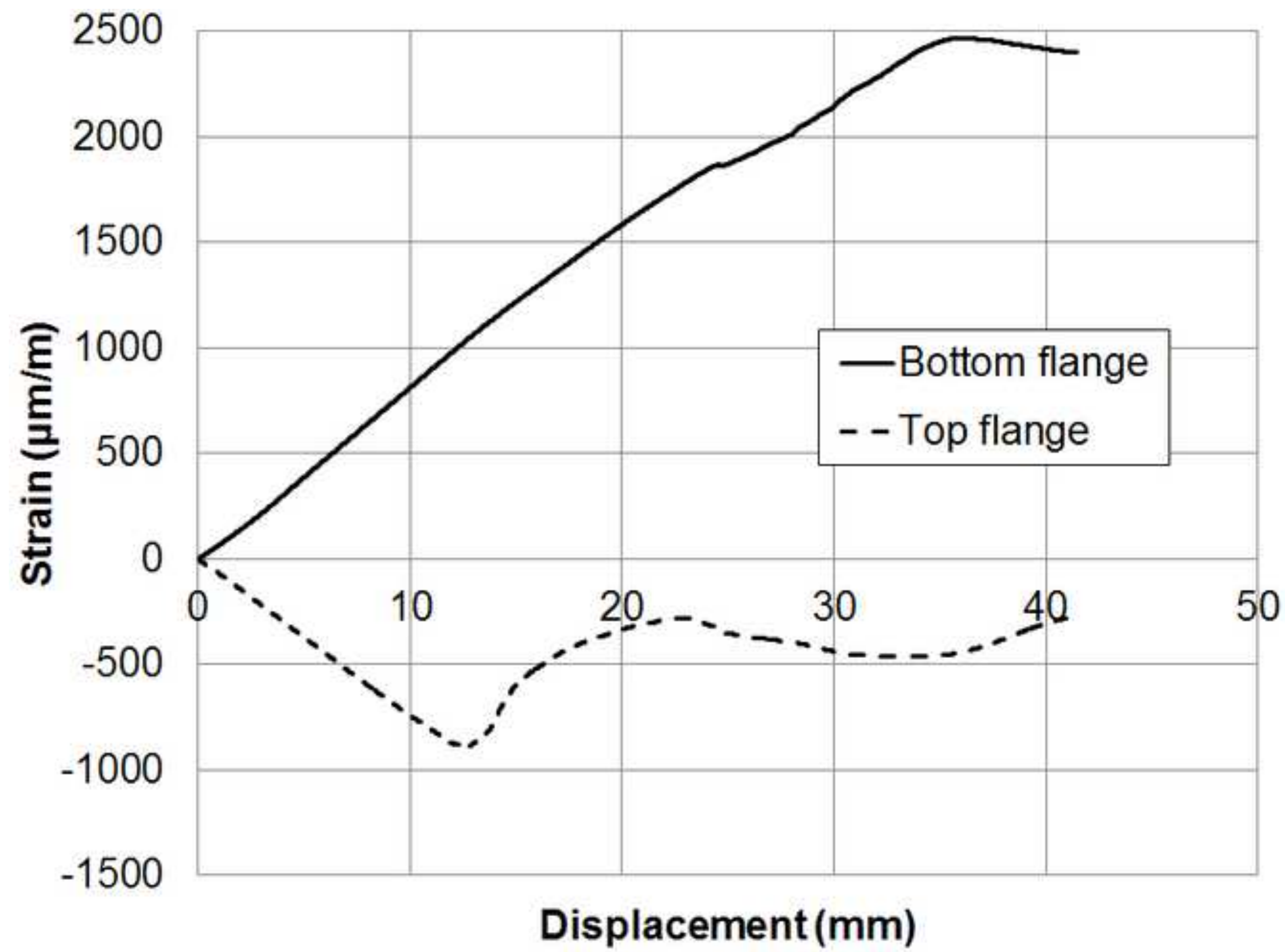




$$
7
$$


Click here to download high resolution image

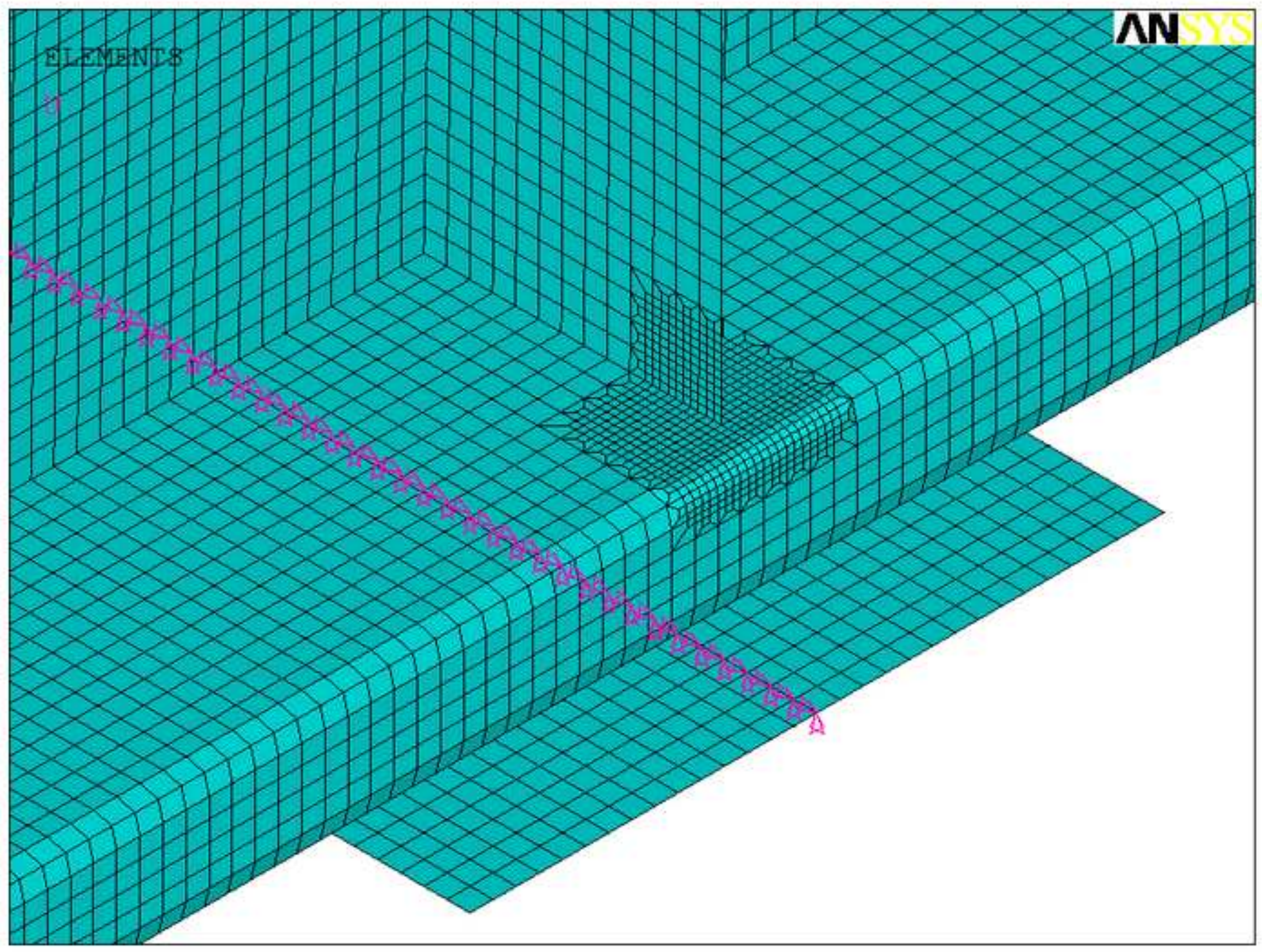


Click here to download high resolution image

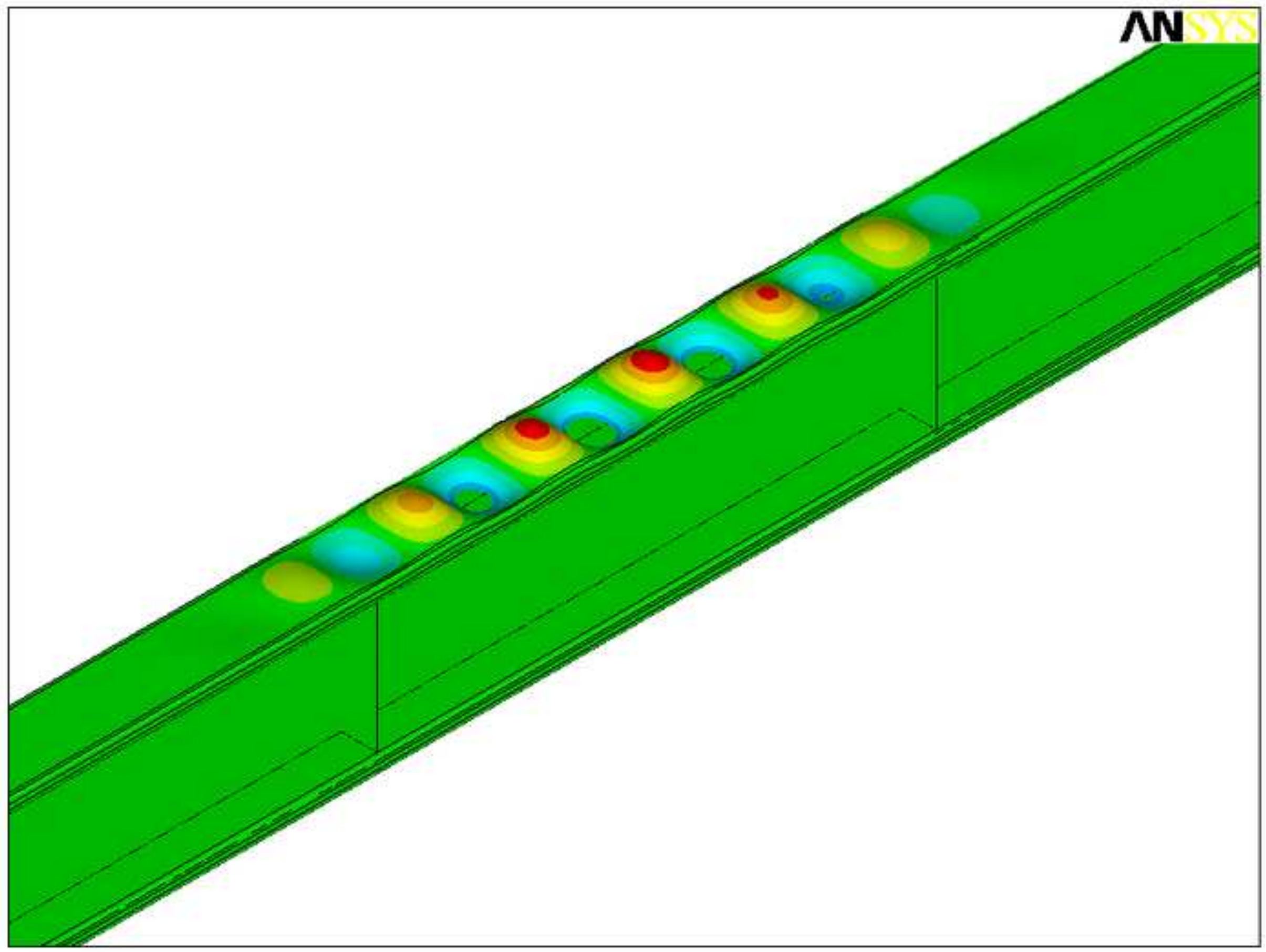

NN 
Figure $15 a$
Click here to download high resolution image
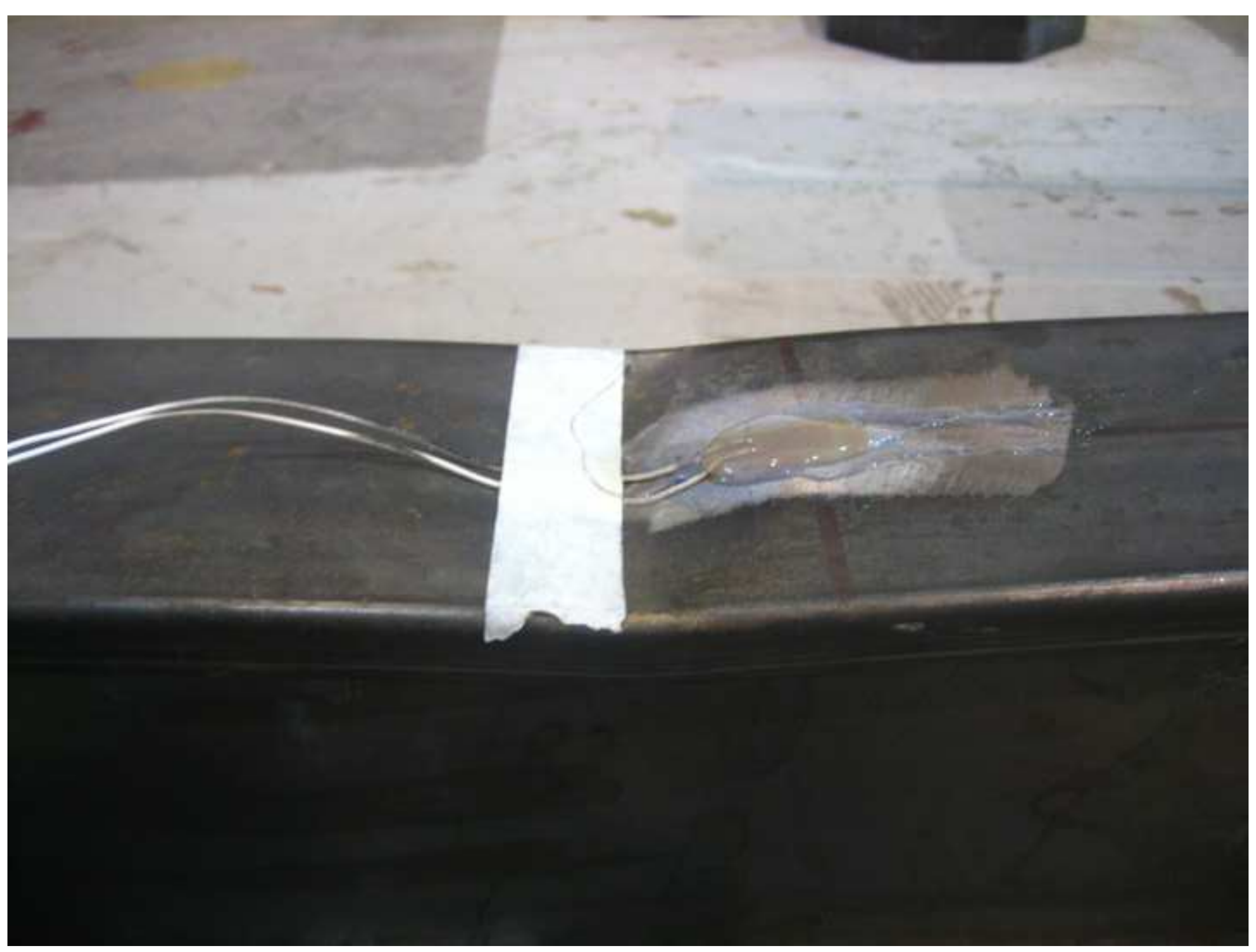
Click here to download high resolution image

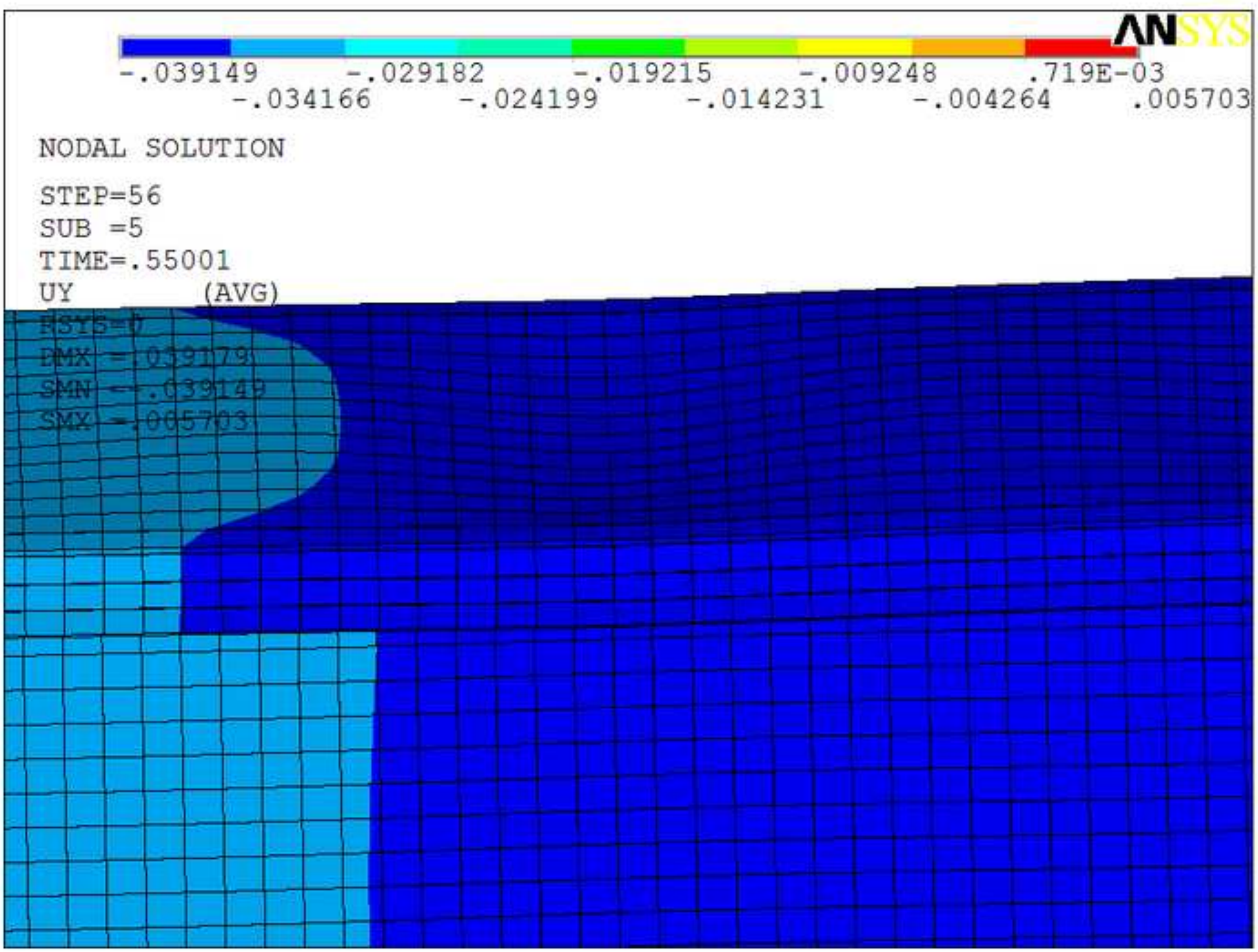


Figure $15 \mathrm{c}$
Click here to download high resolution image

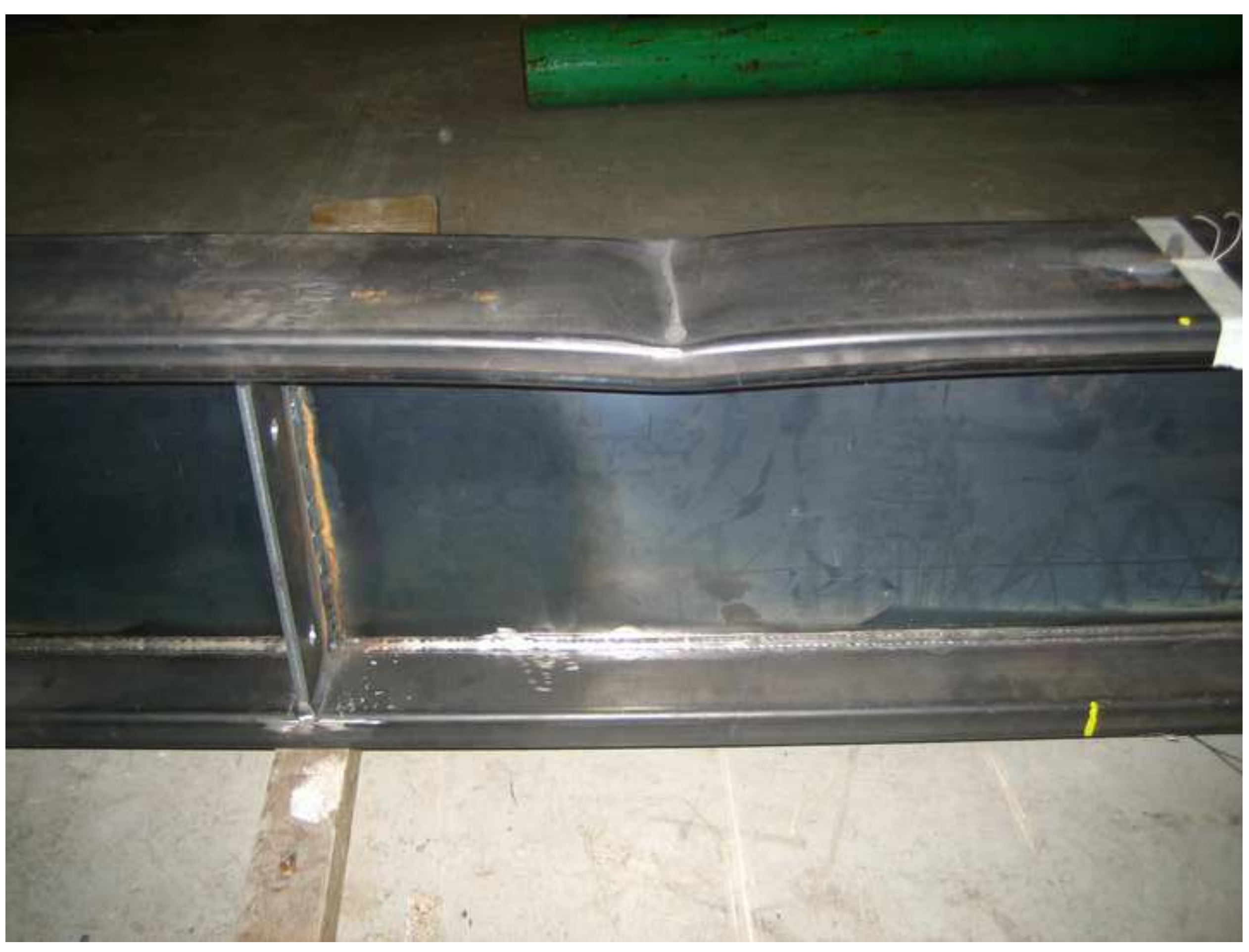




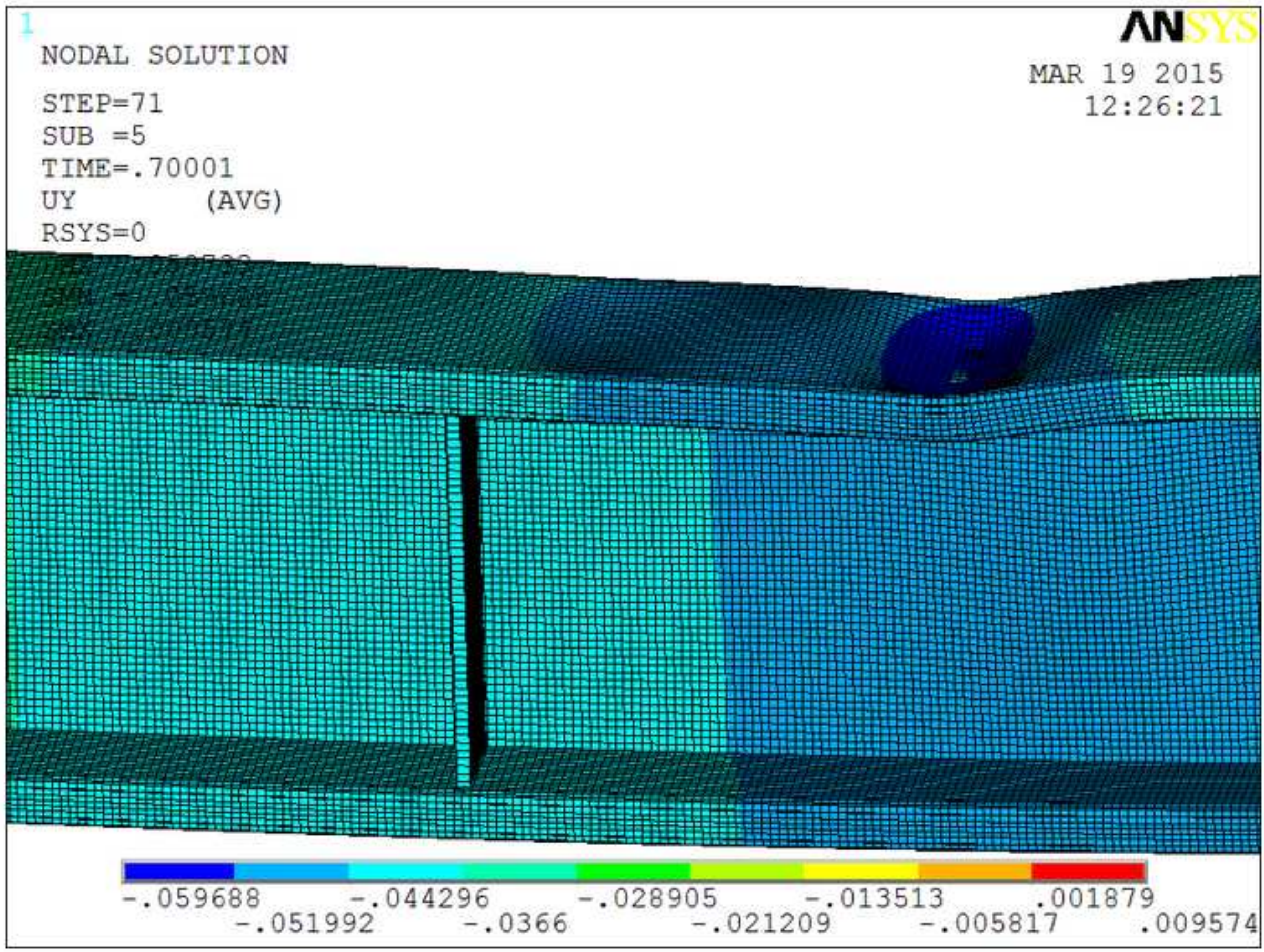

STEP $=7$
SUB $=5$
TIME $=$.

TIME $=.70001$

UY (AVG)

$+2+2$ 乎

$-4 x^{2}+2=2$

\section{MN} $7+$ \# + \#\# $+7$ E

$$
\text { . }
$$


Figure $15 \mathrm{e}$
Click here to download high resolution image

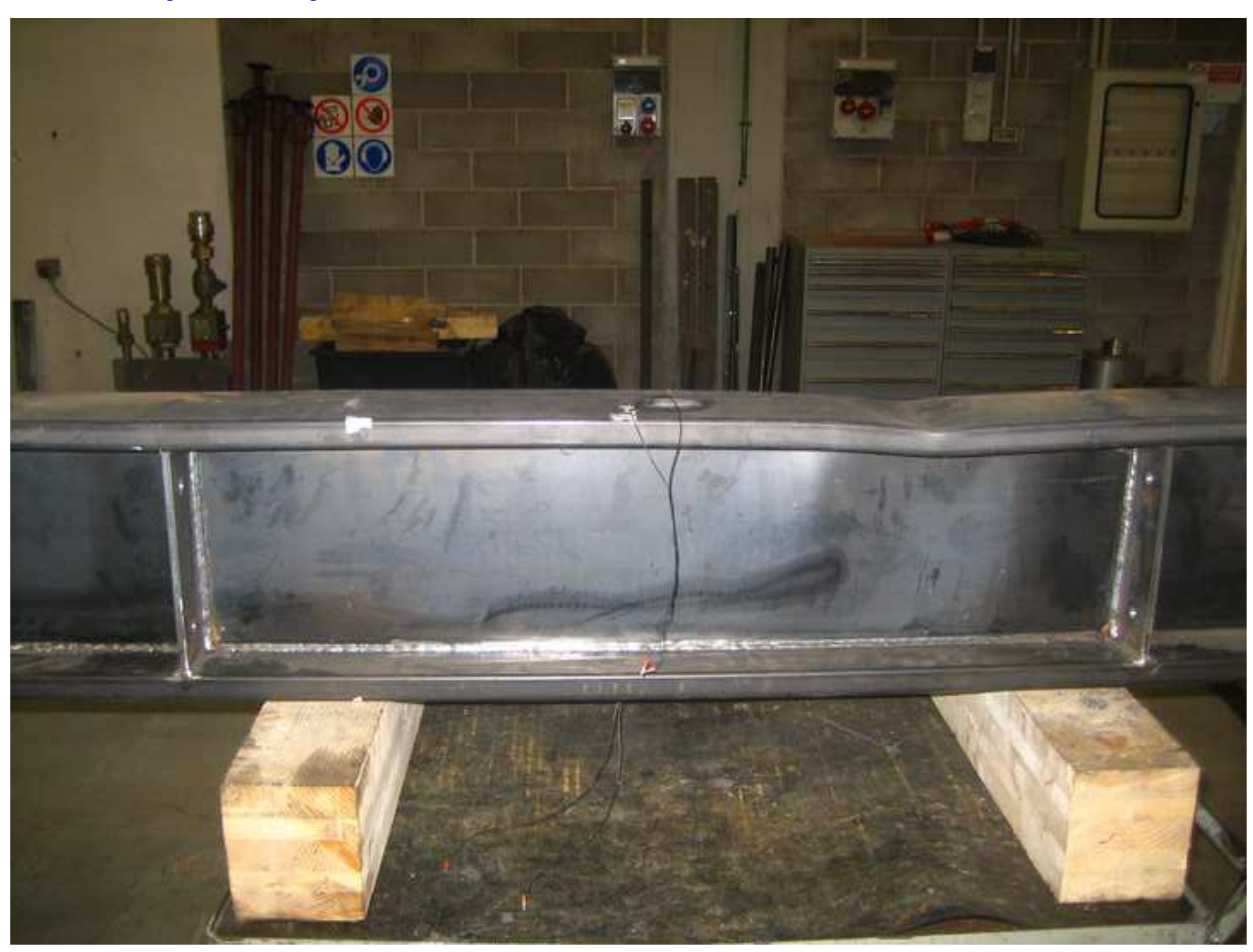


Click here to download high resolution image

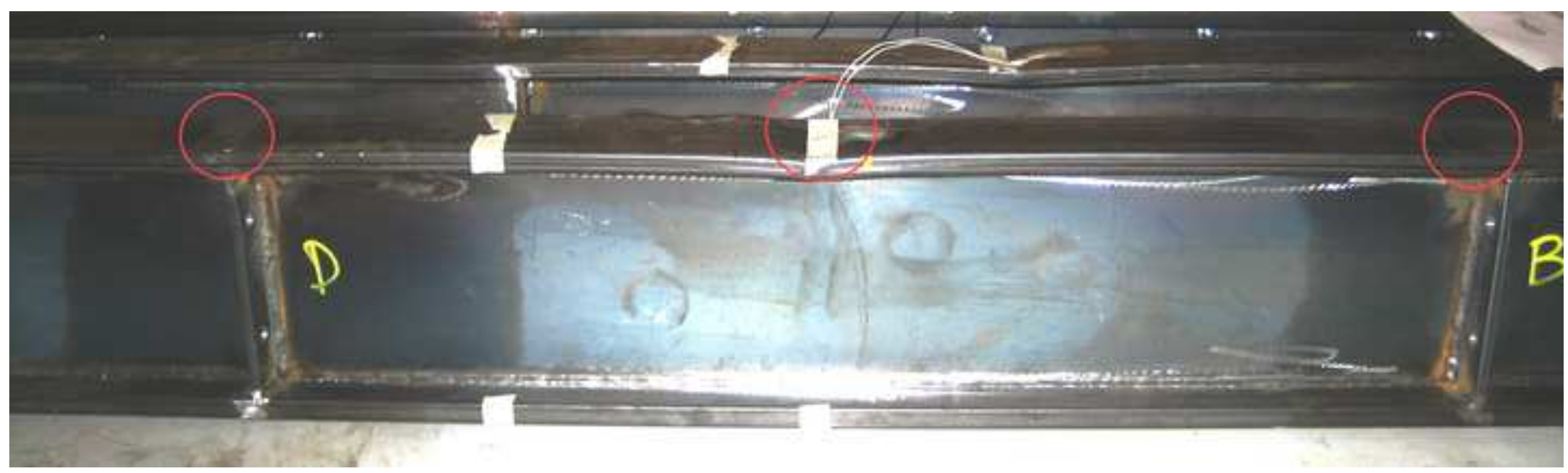


Click here to download high resolution image

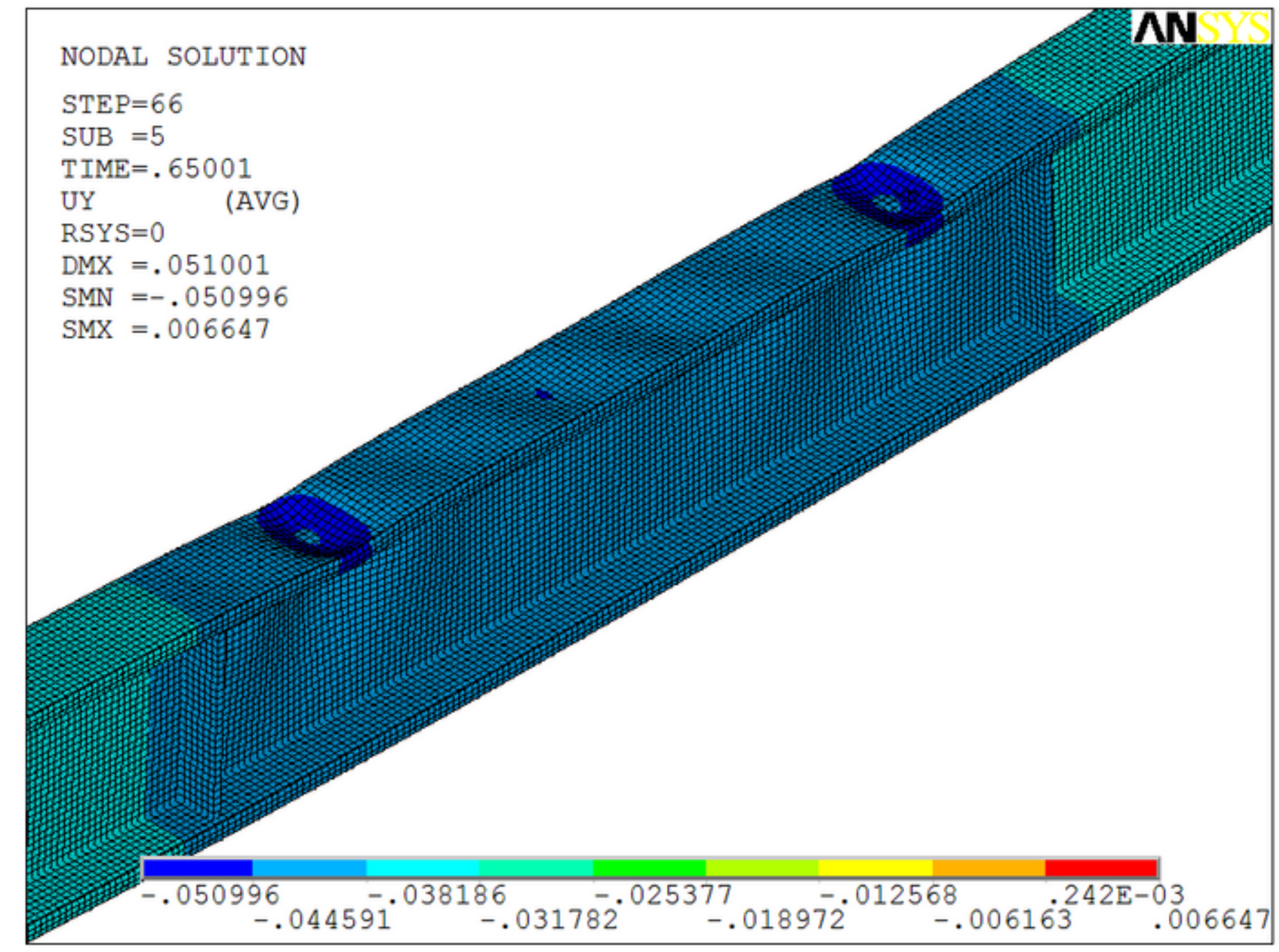




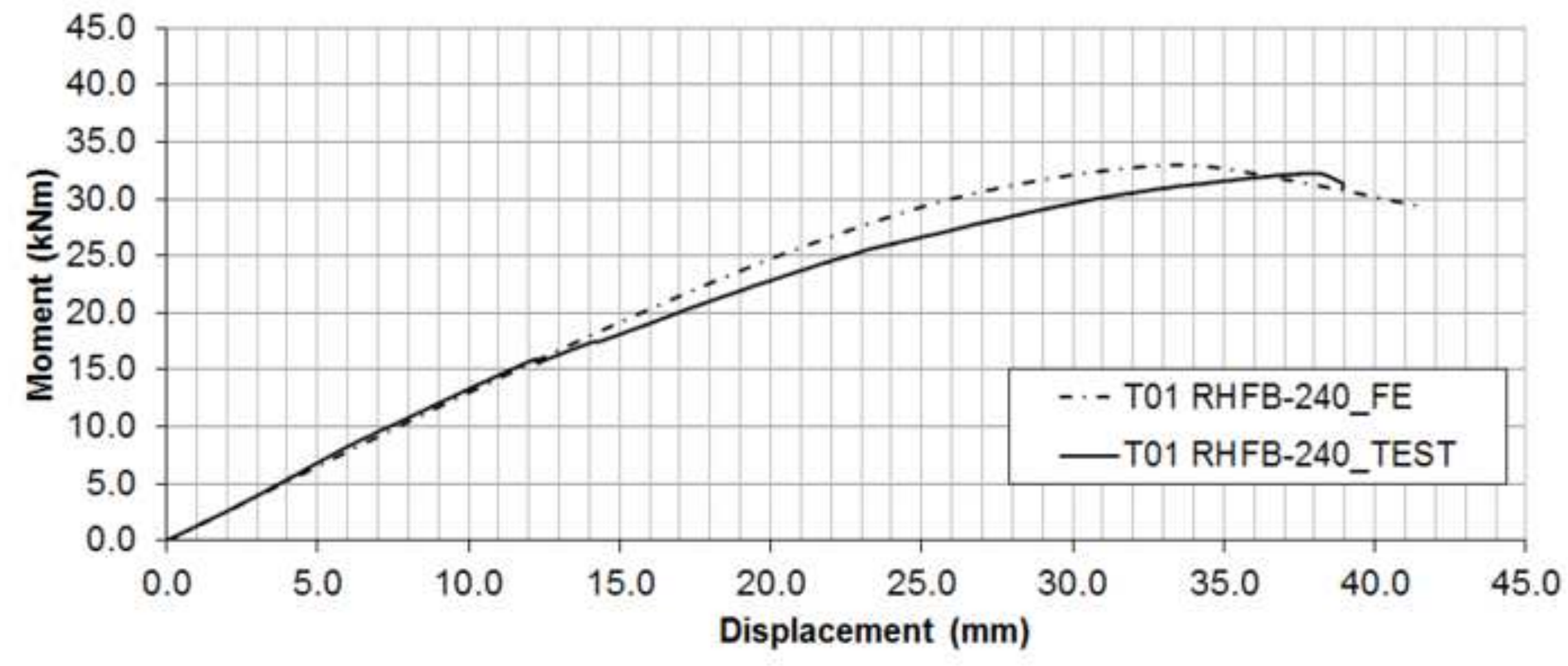




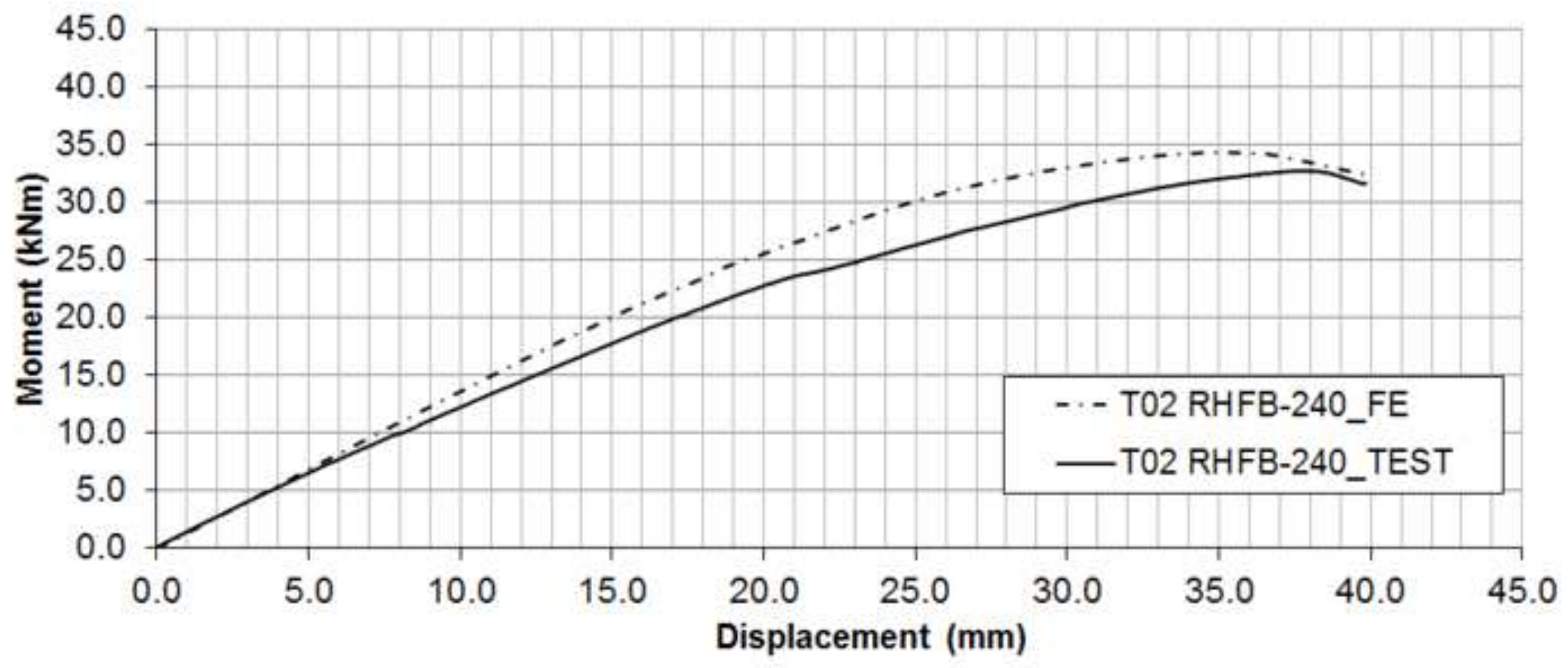




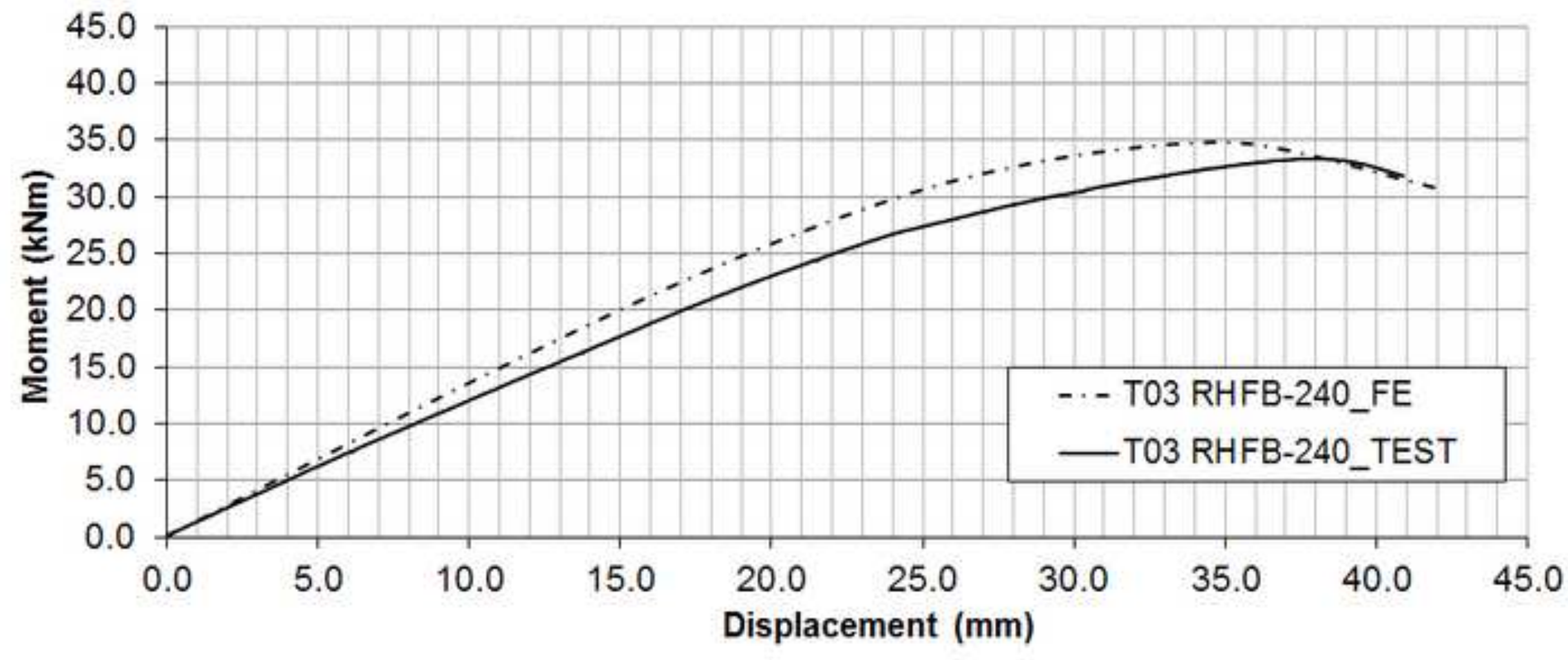


Click here to download high resolution image

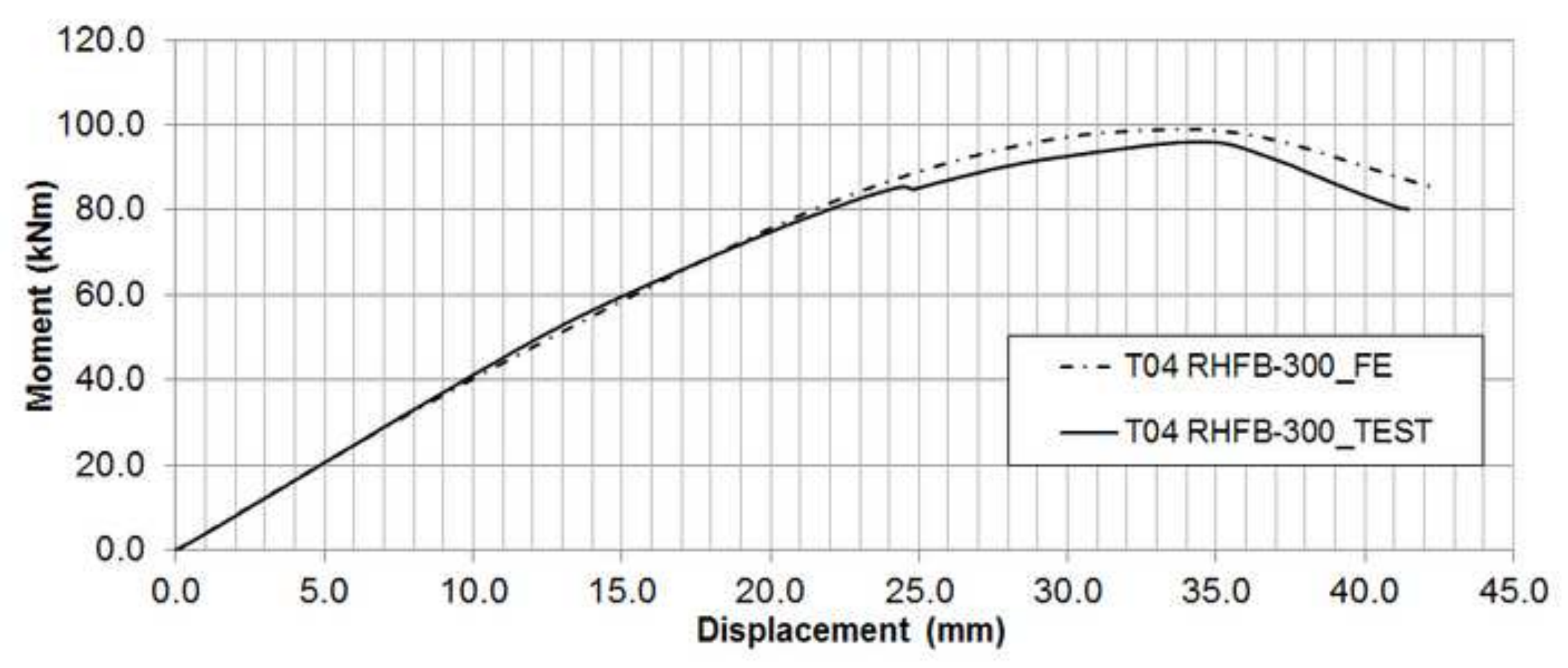


Click here to download high resolution image

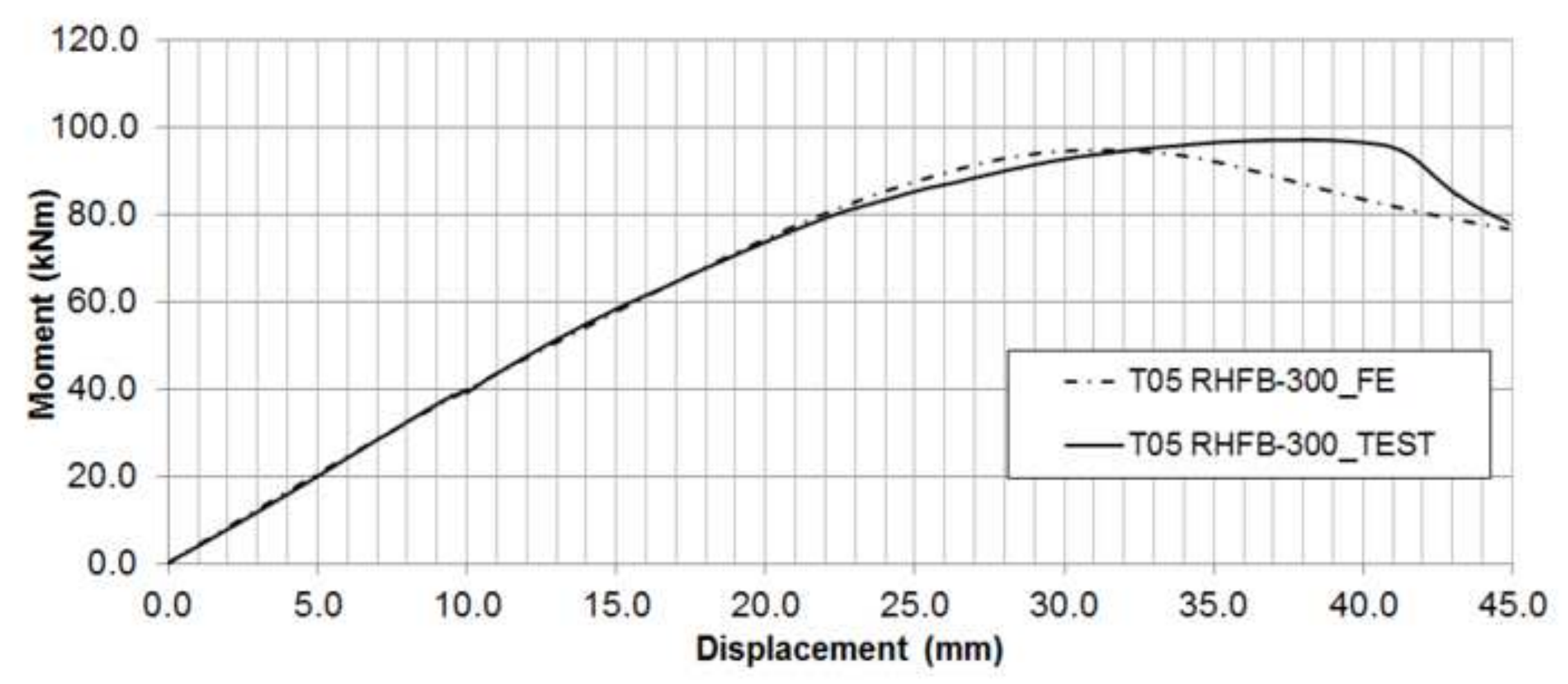




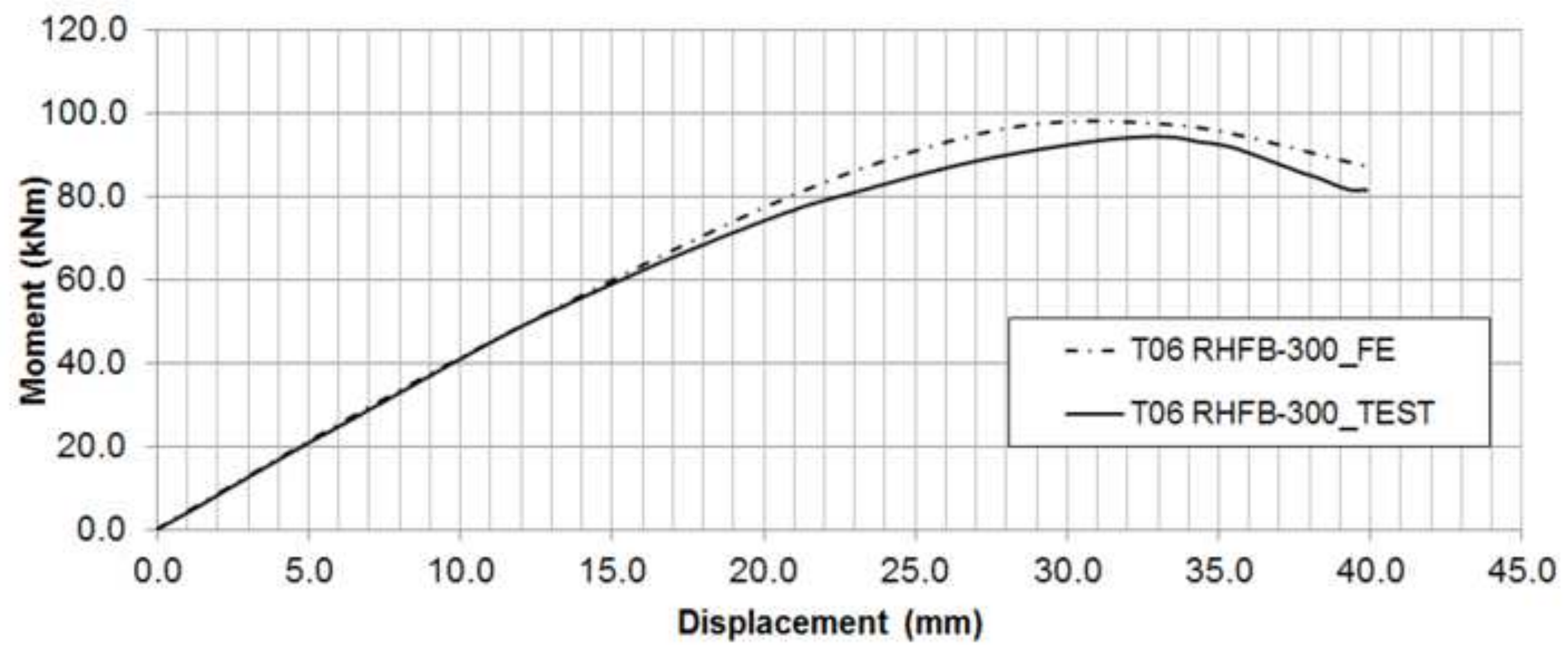


Click here to download high resolution image

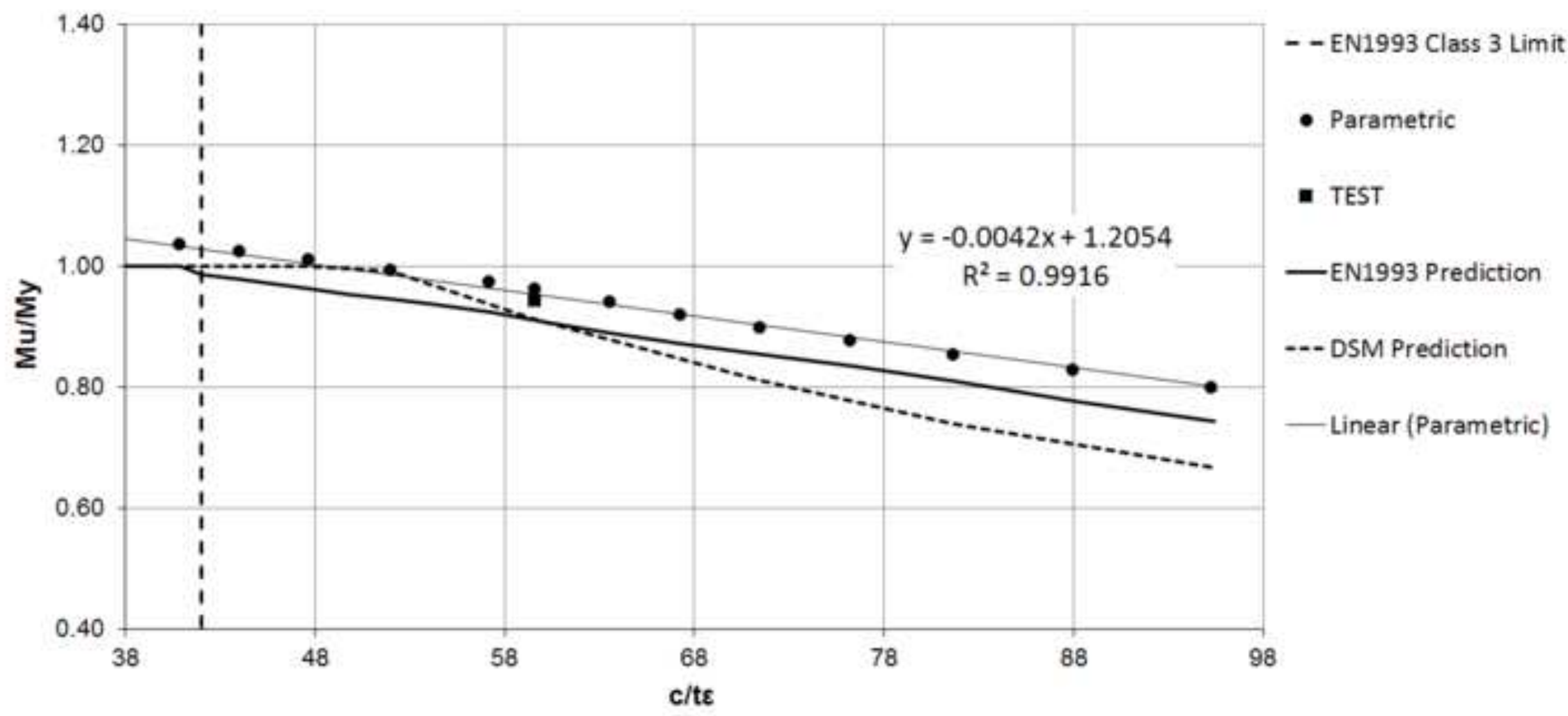


Click here to download high resolution image

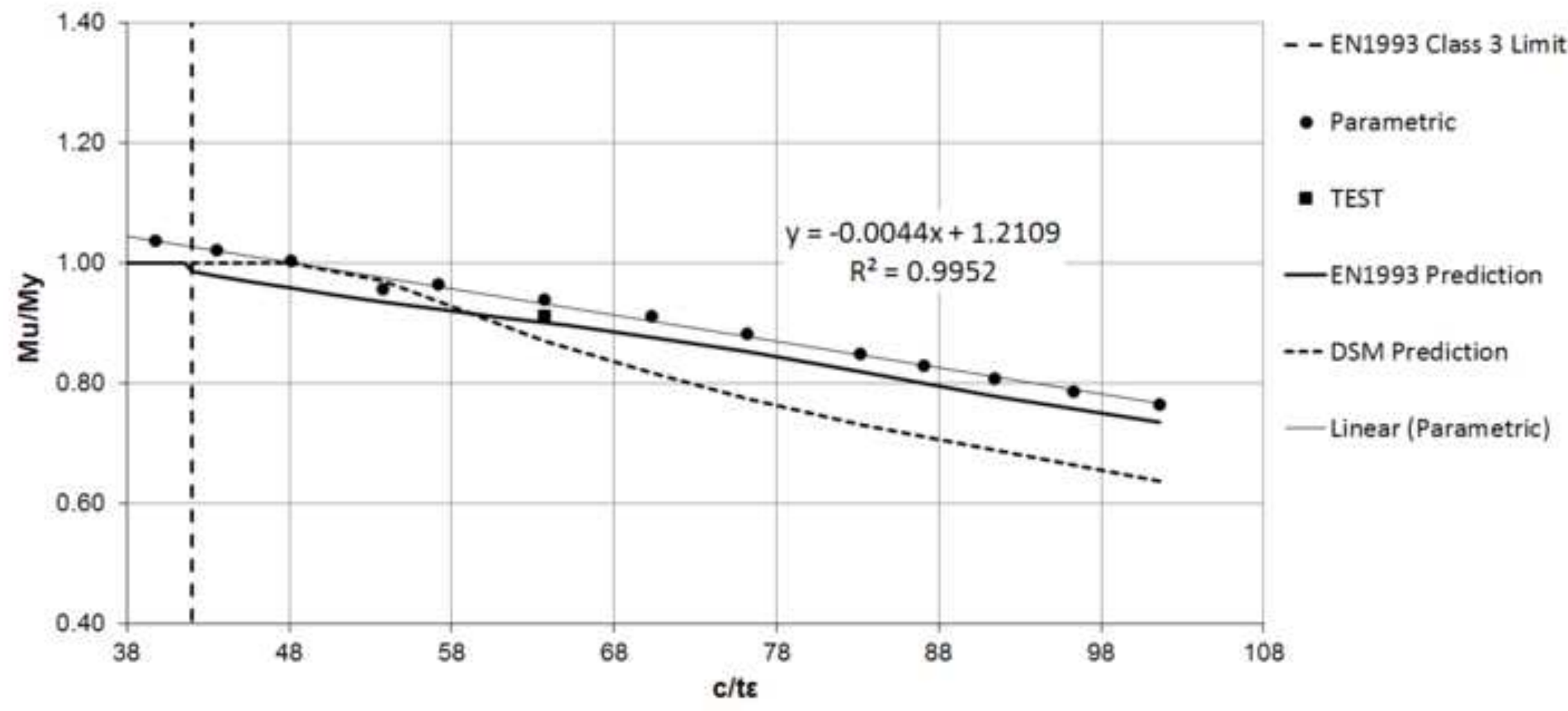


Click here to download high resolution image

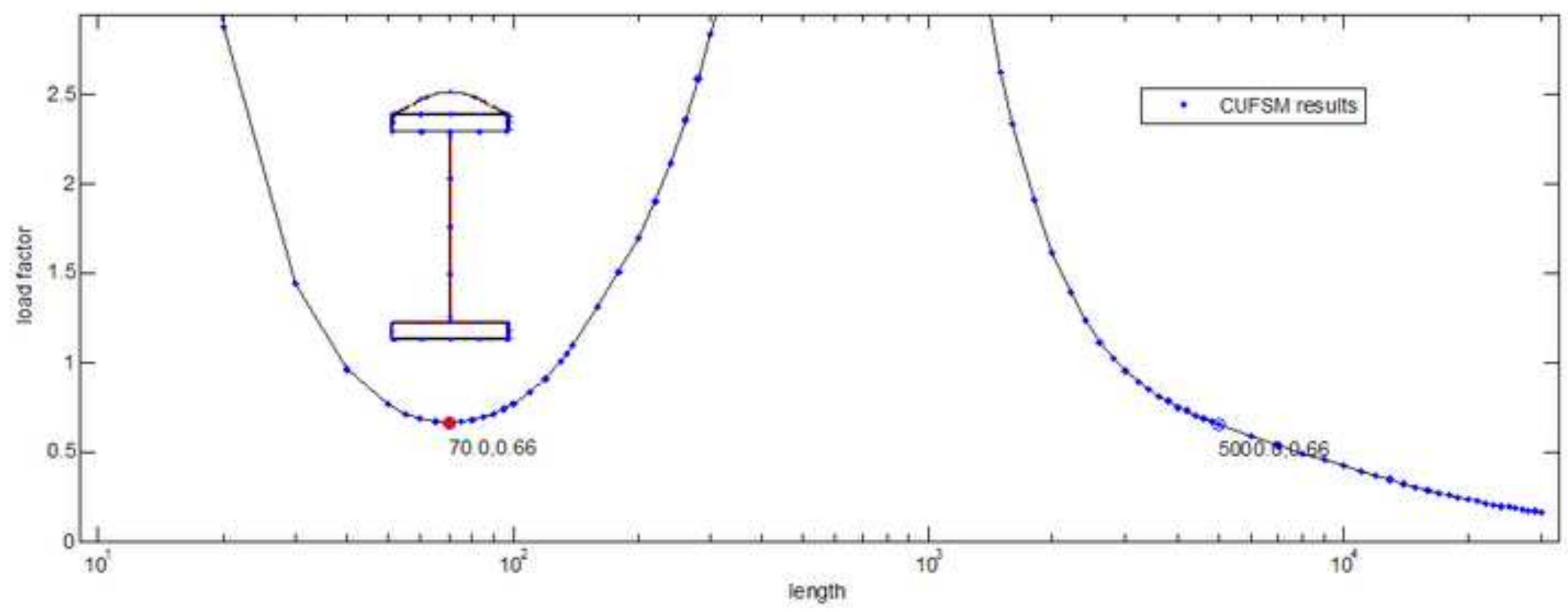


Table 1

Table 1. Nominal section dimensions of the specimens. Dimensions in $\mathrm{mm}$.

\begin{tabular}{lccccc}
\hline & $h_{\text {nom }}$ & $b_{\text {nom }}$ & $c_{\text {t.nom }}$ & $t_{\text {nom }}$ & $L_{\text {nom }}$ \\
\hline RHFB-240 & 240 & 100 & 20 & 2.0 & 4500 \\
RHFB-300 & 300 & 150 & 30 & 3.0 & 4500 \\
\hline
\end{tabular}


Table 2. Measured section dimensions of the specimens. Dimensions in $\mathrm{mm}$.

\begin{tabular}{lcccccc}
\hline & $h$ & $b$ & $c_{t}$ & $t$ & $r_{i}$ & $L$ \\
\hline T01 RHFB-240 & 235.2 & 100.0 & 19.8 & 1.92 & 1.75 & 4495 \\
T02 RHFB-240 & 235.6 & 100.0 & 20.0 & 2.00 & 2.25 & 4495 \\
T03 RHFB-240 & 235.3 & 99.9 & 19.7 & 2.01 & 2.50 & 4495 \\
\hline T04 RHFB-300 & 298.3 & 150.0 & 30.4 & 2.87 & 3.00 & 4498 \\
T05 RHFB-300 & 296.8 & 150.1 & 30.0 & 2.86 & 3.50 & 4496 \\
T06 RHFB-300 & 297.5 & 150.1 & 30.2 & 2.93 & 3.50 & 4498 \\
\hline
\end{tabular}


Table 3. Tensile properties of steel.

\begin{tabular}{lcccccc}
\hline & $\operatorname{avg} f_{\boldsymbol{y}}(\mathbf{M P a})$ & $\mathbf{C O V}$ & $\operatorname{avg} f_{u}(\mathbf{M P a})$ & $\mathbf{C O V}$ & avg $\varepsilon_{f}(\%)$ & $\mathbf{C O V}$ \\
\hline Web & 274.1 & 0.03 & 354.4 & 0.03 & 24.6 & 0.08 \\
Tube flat & 343.3 & 0.02 & 391.0 & 0.03 & 22.5 & 0.21 \\
Tube corner & 439.6 & 0.02 & 476.9 & 0.03 & 7.7 & 0.12 \\
\hline \multicolumn{7}{c}{ RHFB-300 } \\
\hline Web & 258.5 & 0.01 & 355.6 & 0.00 & 25.6 & 0.09 \\
Tube flat & 394.8 & 0.02 & 438.1 & 0.02 & 25.8 & 0.16 \\
Tube corner & 512.2 & 0.06 & 551.8 & 0.07 & 10.6 & 0.06 \\
\hline
\end{tabular}


Table 4. Flexural performance of RHFBs.

\begin{tabular}{ccccc} 
& $\boldsymbol{P}_{\boldsymbol{u}}(\mathbf{k N})$ & $\boldsymbol{M}_{\boldsymbol{u}}(\mathbf{k N m})$ & $\boldsymbol{\delta}_{\boldsymbol{u}}(\mathbf{m m})$ & $\boldsymbol{g}(\mathbf{k g} / \mathbf{m})$ \\
\hline T01 RHFB-240 & 43.0 & 32.3 & 37.6 & 10.0 \\
T02 RHFB-240 & 43.6 & 32.7 & 37.7 & 10.4 \\
T03 RHFB-240 & 44.5 & 33.4 & 37.8 & 10.4 \\
T04 RHFB-300 & 128.0 & 96.0 & 34.2 & 21.2 \\
T05 RHFB-300 & 129.7 & 97.3 & 37.9 & 21.0 \\
T06 RHFB-300 & 125.6 & 94.2 & 32.7 & 21.6 \\
\hline
\end{tabular}


Table 5. Comparison of the flexural behaviour between numerical and experimental results.

\begin{tabular}{ccc}
\hline & $\boldsymbol{M}_{\boldsymbol{u}, \boldsymbol{F E}} / \boldsymbol{M}_{\boldsymbol{u}, \text { TEST }}$ & $\boldsymbol{\delta}_{\boldsymbol{u}, \boldsymbol{F E} \boldsymbol{E}} / \boldsymbol{\delta}_{\boldsymbol{u}, \boldsymbol{T E S T} \boldsymbol{T}}$ \\
\hline T01 RHFB-240 & 1.02 & 0.90 \\
T03 RHFB-240 & 1.05 & 0.93 \\
T04 RHFB-240 & 1.04 & 0.93 \\
T05 RHFB-300 & 1.03 & 0.98 \\
T06 RHFB-300 & 0.98 & 0.81 \\
T07 RHFB-300 & 1.04 & 0.95 \\
Average & 1.03 & 0.92 \\
COV & 0.02 & 0.06 \\
\hline
\end{tabular}

